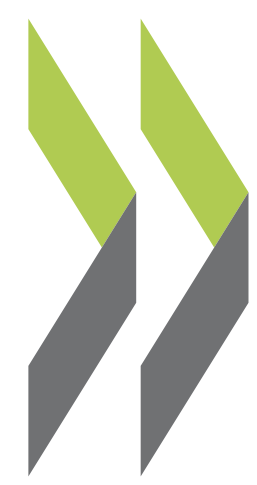

OECD Working Papers on Finance, Insurance and Private Pensions No. 42

Behavioural economics and financial consumer protection
Anne-Francoise Lefevre, Michael Chapman 


\section{OECD WORKING PAPERS ON FINANCE, INSURANCE AND PRIVATE PENSIONS}

OECD Working Papers should not be reported as representing the official views of the OECD or of its member countries. The opinions expressed and arguments employed are those of the authors.

Working Papers describe preliminary results or research in progress by the author(s) and are published to stimulate discussion on a broad range of issues on which the OECD works. Comments on Working Papers are welcomed, and may be sent to mailto:daf.contact@oecd.org or the Financial Affairs Division, Directorate for Financial and Enterprise Affairs, OECD, 2 rue André-Pascal, 75775 Paris Cedex 16, France.

OECD Working Papers on Finance, Insurance and Private Pensions provide timely analysis and background on industry developments, structural issues, and public policy in the financial sector, including insurance and private pensions. Topics include risk management, governance, investments, benefit protection, and financial education.

\section{OECD WORKING PAPERS ON FINANCE, INSURANCE AND PRIVATE PENSIONS}

are published on www.oecd.org/daf/fin/wp

This document and any map included herein are without prejudice to the status of or sovereignty over any territory, to the delimitation of international frontiers and boundaries and to the name of any territory, city or area. 


\title{
Behavioural Economics and Financial Consumer Protection
}

\author{
by \\ Anne-Francoise Lefevre and Michael Chapman, OECD
}

\begin{abstract}
The G20/OECD Task Force on Financial Consumer Protection has highlighted that "regulators and supervisors can use the insights gained through behavioural economics research to inform their approach to potential remedies to help consumers".

This paper, prepared under the aegis of the G20/OECD Task Force, first provides some historical context for the development of the field of behavioural economics and its increased application to policy. It then looks more specifically at the application of behavioural economics in the area of financial consumer protection. Common biases that individuals demonstrate in the context of making financial decisions are identified, and an overview of how numerous governments are testing and implementing the application of behavioural economics for policies promoting financial consumer protection is provided. The paper concludes by highlighting the opportunity for behavioural economics to help provide cost-efficient ways of making policy more effective at promoting positive outcomes for consumers, and stressing the need to continue an open dialogue with policy makers, regulators and supervisors to exchange experiences and good practices.
\end{abstract}

Authorised for release by Pierre Poret, Director, OECD Directorate for Financial and Enterprise Affairs

Keywords: financial consumer protection, behavioural economics 


\section{TABLE OF CONTENTS}

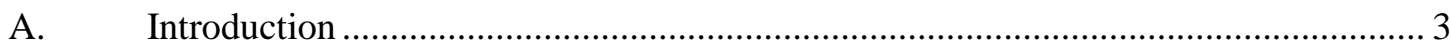

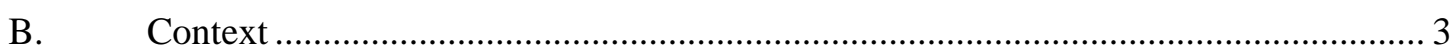

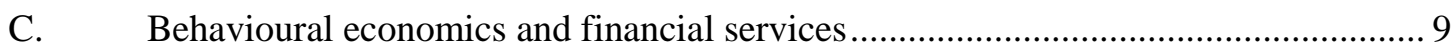
D. Applications in the financial services field ............................................................. 15

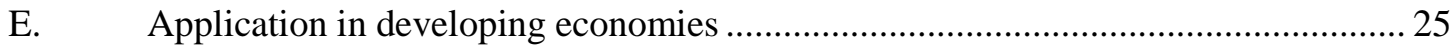
F. Opportunities and challenges for the application of behavioural insights

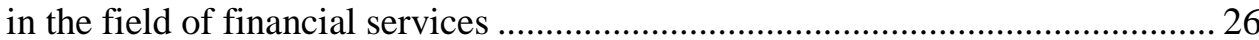

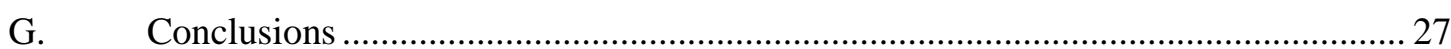

Annex: Compilation and summary of key studies, reports and articles on behavioural economics applied to financial services ...................................... 29

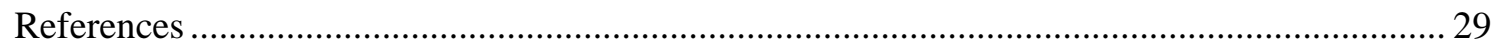

\section{Boxes}

Lessons from behavioural economics for retail financial markets in the UK 10

PRICE Lab: an experiment on how consumers value and compare complex products in Ireland 


\section{A. Introduction}

Having a better understanding of consumers' decision-making processes and of the biases likely to influence their economic and financial decisions are key areas of interest to financial services policy makers, regulators and supervisors. Behavioural economics studies provide a body of knowledge on how people make non optimal economic decisions. By understanding what processes influence consumer behaviour, the harmful impacts of poor decision making by consumers and how to mitigate them can be incorporated into regulatory and supervisors practices to strengthen financial consumer protection.

The OECD has been at the forefront of looking at how behavioural insights can help to make policies more effective and help consumers make better decisions. ${ }^{1}$ Numerous events have been organised and several publications on the topic have been published, notably the most recent publication on Behavioural Insights and Public Policy, which collects case studies from around the world across numerous fields, including on financial products and consumer protection, as a practical reference for policy makers. ${ }^{2}$ Discussions are also occurring around more specific issues relating to financial consumer protection, for example how behavioural biases lead to market inefficiencies and reduced competitive pressure. ${ }^{3}$

As part of this work, this paper describes the basic characteristics and concepts associated with behavioural economics, focusing on behavioural finance insights with the aim of improving financial consumer protection from a supervisory, regulatory and policy-making perspective. It also presents the specific research methods applied in a behavioural economics context, which are largely based on empirical research and randomised controlled trials, with a view to understanding how such techniques have been applied by regulators and supervisors and their effectiveness. It covers all financial sectors and activities (banking, insurance, securities, investment, etc.) and does not specifically focus on retail financial services, as the organisation of wholesale markets and their potential abuses can also have an impact on retail consumers (e.g. market manipulation).

The paper then provides a general overview on how behavioural economics has been applied to financial services, outlining recent developments, ideas and lessons learnt through research and experiences conducted at national level.

The Annex provides an annotated bibliography of a non-exhaustive list of key behavioural economics publications, papers and research documents.

\section{B. Context}

This section of the paper provides the context in which the field of behavioural economics has developed, drawing on key material and publications in order to provide main definitions used in the field and the historical evolution that has occurred.

\footnotetext{
${ }^{1}$ See www.oecd.org/gov/regulatory-policy/behavioural-insights-and-public-policy-9789264270480-en.htm

${ }^{2}$ OECD (2017)

${ }^{3}$ See www.oecd.org/daf/competition/workinprogress.htm\#Beh_Eco
} 
Behavioural economics helps to describe and provide insights into how people fail to behave and make rational decisions and choices in their own best interests. ${ }^{4}$ Human beings do not always take decisions which are consistent with their own preferences and needs, they do not act in a rational way, and their choices are often driven by their emotions and their particular context. Mistaken beliefs, procrastination, passivity, self-control problems, difficulties in choosing among a large set of options are some of the elements which impact consumers' decisions and lead them to choose products or services which are not always best suited to their needs. Building on results from psychological, cognitive and social research into decision making, behavioural economics therefore explores why people make irrational decisions, and why and how their behaviour does not follow the predictions of economic models. ${ }^{5}$

The behavioural economics" view of consumers contradicts the "standard" or "classical" economic assumption according to which individuals know what they want and seek to make the most of the available opportunities given the scarcity of constraints that they face (Camerer, 1999). The classical homo economicus is an ideal and perfect consumer, who knows what is best for him/her, acts thoughtfully and consistently, weighs carefully all options available and makes the best decision to serve his/her interests. This approach deliberately ignores the psychological dimensions of the decision-making process (Angner and Loewenstein, 2006; Heukelom, 2006). However, neoclassical theory has often fallen short of explaining the anomalies that have occurred within market economies ${ }^{6}$.

In contrast, behavioural economics suggests mathematical alternatives based on firm psychological foundations for rationality assumptions. In that sense, it is at the intersection of economics and psychology and seeks to unite the basic principles of neoclassical economics with the realities posed by human psychology (Camerer and Loewenstein, 2003; Camerer, 1999; McAuley, 2010).

In the language of behavioural economists, "bias" refers to the systematic, and most often unconscious, deviations from a strict economic model of rationality that many people exhibit in the face of (economic) decisions. This covers cognitive biases, which include incorrect beliefs or illogical interpretations, social biases such as herding or crowd following, and emotional biases like overconfidence or loss aversion. ${ }^{7}$

The identification of biases and the analysis of the context in which they arise, their specific features and characteristics, and the psychological process leading to them are at the centre of behavioural economics. The list of behavioural biases is therefore continually evolving. Behavioural economics also tries to come up with techniques to prevent, mitigate and possibly reduce the negative effects of biases. One of the most significant mitigation techniques is the framing effect: the way a choice is presented strongly affects the choice that results.

\footnotetext{
${ }^{4}$ It has to be noted that there is no agreed definition of behavioural economics. The broad approach proposed in this paper is aimed at providing a large range of situations and examples to illustrate the relevance of behavioural economics for financial services.

${ }^{5}$ Some researchers have called the attention on the need to also consider the potential bias from financial institutions and regulatory and policy-making bodies which are equally led by human beings (Amstrong and Huck, 2010; Cooper and Kovacic, 2012)

${ }^{6}$ See B. b)

${ }^{7}$ See C. b) for a more detailed presentation of various types of biases.
} 
Regarding the methodology, behavioural economics research is often based on laboratory experiments, which place participants in a simulated environment. These "lab experiments" provide findings of individual economic agents which are difficult to obtain using conventional econometric techniques, and usually take the form of a randomised controlled trial (RCT) ${ }^{8}$ Environmental factors can be fully controlled, in particular all factors affecting decision makers in a given situation. This allows researchers to identify causal relationships. An underlying assumption is that the results generated in the artificial environment of laboratory experiments can be generalised and considered valid in the broader environment. Field experiments, performed outside of a laboratory in real-life situations, have also been used for behavioural economics research. While the results of these studies are usually considered to be more generalizable, the drawback is that all influencing factors cannot be controlled for.

\section{b) Historical significance}

The first conference on behavioural economics was held at the University of Chicago in 1986, and in 1994 Harvard University appointed David Laibson as the first official behavioural economics professor (Pettit, 2014). Universities, research organisations and business schools have fairly recently recognised behavioural economics as a (sub)discipline.

However, the notion of psychology as a driver of economic action is not new. Already in the $18^{\text {th }}$ century, Adam Smith noted in The Theory of Moral Sentiments (1790) that the imperfections of human psychology did have an impact on economic decisions. He anticipated a wide range of insights regarding phenomena such as loss aversion, overconfidence or fairness. But until the middle of the $20^{\text {th }}$ century, economics was dominated by the neoclassical approach based on the theory of a perfect, rational homo economicus. The ambition was to elevate economics as a natural science, and psychology had to be considered separately. Some economists (such as Francis Edgeworth, Irving Fisher or Vilfredo Pareto) included a psychological dimension in their research, but they were given limited attention at the time. For example, Pareto (1935) highlighted that one of the central causes of the 1929 stock market crash and the ensuing Great Depression could be the human factor in economic decision-making.

Post-war economists (for example, Samuelson, 1947 or Arrow and Debreu, 1954) adopted the belief that the only valid method to collect information about human choices and preferences was to study market transactions or other observable choices. On that basis, the expected utility and discounted utility models, which review decision-making given uncertainty and intertemporal (or delayed) consumption, gained acceptance. Maurice Allais (1953) built on this work and demonstrated experimentally that in a context of risky outcomes, the key factor for the decision-maker is the risk level of the selected option. This result contradicts the expected utility hypothesis - the mathematical view of probability being considered in human behaviour - and is known as the "Allais paradox". First presented in 1953, it led to multiple developments in decision theory and behavioural economics. Another important milestone was the publication of Models of man, social and rational by Herbert A. Simon in 1957, who introduced the concept of "bounded rationality". He demonstrated that humans' decision-making capabilities were limited by the information available, their capacity to evaluate this information and the amount of time they had to make the decision.

Progressively, economists recognised that counterexamples to their theoretical models, evidenced by experiments, could not be ignored, and progress in research in psychology identified new directions

\footnotetext{
${ }^{8}$ See C. b) for a more detailed presentation of RCTs.
} 
for development. One of the key turning points for behavioural economics was probably the work of psychologists Daniel Kahneman and Amos Tversky at the end of the 1970's, who explained the psychological reasoning behind certain non-rational economic decisions in their paper Prospect Theory: An analysis of decision under risk (1979). They found empirically that people underweight outcomes that are merely probable in comparison with outcomes that are obtained with certainty, and also that people assign value to gains and losses rather than to final assets. Prospect theory has a solid mathematical basis, making it comfortable for economists to use.

Two publications by Richard Thaler and Cass Sunstein fostered today's recognition of behavioural economics and contributed to broadening its influence beyond the academic world. First, in 2003 Libertarian paternalism established that given the behavioural findings of bounded rationality and bounded self-control, people's choices could be steered in welfare-promoting directions without eliminating their freedom of choice. Second, in 2008 Nudge expanded on this concept and highlighted numerous examples where people could be "nudged" to make better decisions using these behavioural insights without restricting their option set. By illustrating how behavioural insights could be put to practical use, these books have been a major source of inspiration for policy makers and business people.

\section{c) Behavioural economics and public policy}

Behavioural economics has potential applications in all fields involving human decisions and choices, particularly where relatively complex products or services are involved. Jurisdictions pioneering in the development of behaviourally informed policy or regulation have already taken initiatives in many different areas such as healthcare, food and energy labelling, organ donation, charitable giving, energy use, employment activation, fine recovery, etc.

Therefore, behavioural economics has now reached a level of maturity and development which has led to its progressive recognition as a (sub)discipline with potential applications across various public policy fields involving human decisions and choices (Dolan et al., 2010; Lunne, 2014).

This is because, first, there is now a substantial set of confirmed evidence on what people's main biases are and how their behaviour is influenced, and second, recent economic events (for example the subprime mortgage crisis, or pension mis-selling) can neither be explained nor understood without psychological insights which go beyond established notions of "rationality". On this basis, there is growing recognition that the findings of behavioural economics can help to identify areas where government intervention can be more effective than was the case with traditional economic models. Behavioural economics can provide a more realistic and thoughtful basis for making economic policy. This has to be combined with a series of contextual elements which explain why behavioural economics increasingly influences the focus and shape of public policy initiatives:

- Some of the biggest policy challenges - people with chronic health conditions, obesity, environmental sustainability - require changes in people's behaviours, lifestyles or existing habits. This does not always require a hard instrument such as legislation or regulation which compels people to act in a certain way. Including less coercive and more effective tools aimed at changing the environment within which people make decisions and respond to cues can be used, with the potential to bring about rapid, significant and long-lasting changes in behaviour.

- The recent financial crisis and its long-lasting impact on markets have provided evidence of the limitations of deregulation and of the "markets-do-it-best" approach. Markets do not operate perfectly and individuals do not always follow the most economically rational path 
and addressing behavioural bias through behaviourally informed solutions can help consumers make informed decisions and minimise losses arising from human errors.

- Governments operating with budgetary constraints require robust cost-effective and efficient solutions to tackle market failures. Innovative public policy initiatives have to be considered, as complementary or alternative tools to conventional "hard" instruments such as regulation, legislation or taxation. In this respect, behavioural approaches provide low cost, new ways of acting and helping achieve better outcomes for citizens.

\section{OECD work on behavioural insights}

The OECD expressed support early on for the applications of behavioural economics to policy and has since given much attention to the improvements it could bring to public policy decision making, regulation and rule-making.

\section{Consumer policy}

In 2010, the Consumer Policy Toolkit noted that work done in the field of behavioural economics had identified a number of important ways that consumer behaviour may deviate from the assumptions underlying the traditional market model and enriched understanding of consumer behaviour in key areas (e.g. making choices with uncertain outcomes, trade-offs between present decisions and longterm interests). It also underlined that in certain areas, such as designing information disclosures or evaluating situations involving default-setting, behavioural economics may provide important insights that could improve policy formulation. It recommended that, as behavioural economics continues to mature, much attention should be given to further implications for consumer policy.

In 2014, the OECD report on Regulatory Policy and Behavioural Economics offered an international review of the initial applications of behavioural economics to policy, with a particular focus on regulatory policy. It described the extent to which behavioural findings have begun to influence public policy in a number of OECD jurisdictions, referring to a total of more than 60 instances. It illustrated that some jurisdictions have introduced a behavioural dimension in their public policy approach as a general guiding principle on better policy-making, or on a case-by-case basis (Australia, Canada, the European Commission, Ireland, Italy, the Netherlands, UK, USA). ${ }^{9}$ It also indicated that some other jurisdictions have shown interest and are exploring how best to use behavioural economics findings in their policy-making approach (France, Norway). The report also considered possible lessons for regulatory design and delivery. It highlighted in particular how much the environment in which decision makers operate matters, and how good regulations can improve the environment, and in this context should be viewed as an enabler and a facilitator to achieving positive outcomes.

The study also outlined that behavioural economics influences the general approach to public policy as well as the solution(s) to the identified market problems. Improved knowledge of consumers' psychological traits and decision-making processes impacts the policy vision and strategy, its targets, its objectives, etc. It also helps determine what is/are the most effective way(s) to remove the existing

\footnotetext{
9 "Explicit mechanisms for applying behavioural economics to policy might be contrasted with more implicit ones, whereby understanding of behavioural economics is spread more broadly among policy makers across a sweep of institutions within the public sector. Instead of a group of individuals with specialist knowledge seeking to apply behavioural ideas across policy areas, it may be possible for policy makers within these areas to absorb and apply behavioural thinking." (Lunne, 2014)
} 
problems, and this can include a wide range of options, from the provision of selected information to regulation, or some form of alternatives to regulation, or ultimately to the control of products. It is important to have in mind that adopting a behaviourally-inspired approach does not come as an alternative to regulation. It provides an additional tool to design proper regulation when it proves to be the most appropriate solution. In this case, behavioural findings will also impact the scope, the shape, the nature and the focus of the regulatory provisions, possibly built on a nudge.

\section{OECD initiative on "New Approaches to Economic Challenges" (NAEC)}

NAEC was launched by the OECD in 2012 as a comprehensive organisation-wide reflection process on the roots and lessons from the crisis, as well as long-term, global trends. NAEC was also launched as part of a broader effort to build an inclusive and sustainable agenda for growth and wellbeing. The NAEC process involves renewing and strengthening the OECD's analytical frameworks, policy instruments and tools. This new approach needs to take into account the changing context, and in particular the fact that the crisis has provoked changes in some of the assumptions about the functioning of the economy, and especially those related to the behaviour of economic agents and to risks, paying greater attention to psychological bias, perceived versus objective risks, as well as the nonlinearity in risk perception.

OECD work on behavioural economics is therefore expanding, particularly in the areas of public governance, regulatory policy, consumer policy and environmental policy design. The Public Governance and Regulatory Policy Committees are also developing a policy toolkit which will include some guidance on the application of behavioural economics in policy-making. Further work is under discussion in other policy areas such as tax policy. The OECD convened a meeting in 2015 of behavioural insights practitioners in governments and regulatory agencies as a platform for sharing the experiences applying behavioural approaches to policy. This will help in building and sharing knowledge on how and where behavioural economics can contribute to policy making. The platform will contribute to developing good practices in applying behavioural insight, reflecting on what works and why, and what are the short- and long-term effects of interventions.

\section{Pensions}

The OECD also released a paper in 2007 on the Implications of behavioural economics for mandatory individual account pension systems. In individual account pension systems, members bear the risks and consequences of their investment decisions. In most cases, these accounts have partially replaced public pension systems, raising concerns over their impact on retirement income. The paper described the extent to which plan members make active investment decisions in their pension systems and assesses the policy solutions that have been put forward to facilitate choice. The paper offers a comparative analysis of ten countries that have implemented investment choice in the accumulation stage of their individual account pension system.

Key conclusions from the study are that, although a basic assumption of economic theory states that consumers are better off with a wider array of choices, too many investment options can cause information overload, resulting in greater confusion and complexity, and, consequently, in a greater use of the default option. The design of the default option matters, since even when choice is limited, an important group of participants do not exercise active choice. Moreover, many participants may interpret the default option as the relevant one for them, as it has been endorsed or proposed by policymakers. Policy makers need to urgently address how default investment options should be designed and specifically consider new types of default options, such as managed accounts and target date funds. Evidence also reveals a preference among members towards equity funds. Participants tend 
to change their asset allocation on the basis of recent performance trends and engage on naive diversification strategies, such as equal weights across funds irrespective of their asset allocation.

In 2008, the OECD indicated in a report on financial education and awareness in the field of pensions that improved financial education is the appropriate response if a lack of financial information or skills is the reason for low levels of saving. But it also confirms that an increasing number of studies in behavioural economics show that financial and savings behaviour relate to psychological factors. These findings, therefore, show heterogeneous savings behaviour across consumers, which have important implications for the design and implementation of effective financial education programmes. For example, in order to meet the needs of those consumers who are "non-planners", financial education programmes will need to emphasise simpler decisions and tangible present-day (as opposed to a future day) benefits, using explicit and direct information, reduced complexity, and fewer choices. Yet even these directed schemes may not be sufficient, and other measures may be required to ensure an adequate level of savings for retirement, for example automatic enrolment, with appropriate default options with respect to contribution rates and investment allocation.

Financial Education and Literacy

Under the support of the Russia/World Bank/OECD Trust Fund for Financial Literacy and Education, the OECD has raised awareness on the importance of behavioural economics in the financial education context. The report (Financial literacy and education Russian Trust Fund 2013) explored how the design of financial education programmes can benefit from the findings of behavioural economists and economic psychologists. In particular:

- It gathers a review and discussion of the literature on how behavioural economics can improve and complement financial education visually and how it can help the design of financial education programmes.

- It provides an in-depth case study of an innovative application of lessons from psychology to a financial education programme in Brazil.

\section{Behavioural economics and financial services}

\section{a) Specific relevance of behavioural economics/psychology for financial services}

\section{Consumers' behavioural problems are accentuated when making (difficult) financial decisions}

Using behavioural economics insights to better protect consumers involved in financial transactions seems of particular relevance given the complexity of financial products and services for an average consumer, and the large array of choice. Comparison between products is difficult, as each of them has specific features, and pricing structures are not always fully transparent. Besides, financial choices are usually important life decisions for consumers involving emotional elements (e.g. investing a lifetime savings, planning for retirement, purchasing insurance involving death benefits). An additional aspect is that decisions made will only produce their effects over the long-term, meaning that risk and uncertainty can play a larger role. It is also difficult for consumers to learn from experience, as financial products are often one-off purchases (FCA, 2013; Lunne, 2014). These difficulties are accentuated when consumers are older or vulnerable due to their physical or mental condition, their economic circumstances, their family situation, their age, etc. 
In the Netherlands for example, the financial regulator came to the conclusion that because of the limited time and motivation consumers allocate to financial decisions, disclosure requirements alone are not effective enough in informing and improving consumers' decision making. These insights resulted in a desired shift of responsibility between firms and consumers. Firms need to have a more active and responsible approach in order to safeguard the interests of consumers. An example of this shift concerns saving agreements, where customers were lured in with high interest rates that were quietly reduced month-by-month over the years that followed to unrealistically low levels. This kind of product would not have existed if customers had assessed their financial products more actively and switched to a provider with a more favourable interest rate. However, this did not happen. The Authority for the Financial Markets (AFM), the Dutch regulator, came to an agreement with market parties that these saving agreements are harmful for customers and they should no longer exist. ${ }^{10}$

Today, with rapidly evolving technologies, consumers benefit from an extended range of distribution channels to buy financial services and products, especially mobile phones and the internet, and different access points can even be combined. With more opportunities come more risks, in particular in terms of fraud but also regarding the information provided to consumers. It is challenging for consumers to find and analyse relevant and accurate information in their particular context, and assess what information can be trusted. It is therefore particularly important that consumers benefit from an equivalent protection regardless of the channel they use to purchase their financial product or service.

For all of these reasons, behavioural biases are common in consumers' financial decisions, and can have significant short-term and long-term impacts on the well-being of consumers and of their families. People often make errors when choosing and using financial products, and can suffer considerable losses as a result. Using behavioural economics helps to explain how these errors arise, why they persist, and what can be done to prevent them. Market forces left to themselves will often not work to reduce these mistakes, so regulation may be needed.

Behaviourally-inspired policy and/or regulatory responses to remedy the most frequently made errors can therefore be particularly useful for the area of financial consumer protection.

\section{Box 1. Lessons from behavioural economics for retail financial markets in the UK}

In 2013, The Financial Conduct Authority (FCA) published a research paper that summarised the main lessons from behavioural economics for retail financial markets:

- Consumers make predictable mistakes when choosing and using financial products - the most relevant biases for retail markets are listed and categorised according to how they affect decisions: preferences (what we want - present bias, reference dependence and loss aversion, regret and other emotions), beliefs (what we believe are the facts about our situation and options - overconfidence, over-extrapolation, projection bias), and decision-making (which option gets us closest to what we want, given our beliefs - framing, salience and limited attention; mental accounting and narrow framing; decision-making rules of thumb; persuasion and social influence).

- $\quad$ Firms respond to these mistakes and how behavioural biases can lead firms to compete in ways that are not in the interests of consumers.

The research paper then describes how behavioural economics can, and should, be used in the regulation

\footnotetext{
${ }^{10}$ www.oecd.org/daf/fin/financial-education/G20-OECD-Financial-Consumer-Protection-PrinciplesImplementation-2014.pdf, Principle 3
} 
of financial conduct following 3 steps:

- $\quad$ Step 1: Identifying and prioritising issues - establish a set of indicators that can help identify where consumer detriment from mistakes may be particularly high, with regard to firms (e.g. uncompetitively high margins, concentrated profits from a small group of consumers), to product features (e.g. innovative products that appear very cheap, contract features that often target behavioural biases) or to consumers (e.g. reported or potential regret, choice out of line with common sense). A complementary way is to look at a potential mismatch between the need the product is meant to serve and how consumers use it in practice. The size of the problem should be the main priority driver.

- $\quad$ Step 2: Identifying root causes of problems - investigate whether consumers are making mistakes and if so which bias(es) are the cause (examine consumers choice in different settings, their awareness of product information, their self-reported needs and objectives), and determine the extent of the issue firm-specific or market-wide - to define the type of response needed.

- Step 3: Design effective interventions - ordered from least to most interventionist, behavioural problems could be solved through 1) the provision of information in a specific way, or the prohibition of specific marketing materials or practices; 2) changes to the choice environment; 3 ) the control of product distribution and 4) the control of products, including ban on specific product features or requirement for products to contain specific features.

Inconsistencies in consumers' decisions can have an impact on how markets work

Behavioural economics can also be used to support competition in financial services, for the benefit of consumers as end-users of the services.

When consumers' decisions are over-influenced by behavioural bias, firms do not compete on the quality and price of their commercial offer or on the innovation or diversity of their products and prices. They compete in ways that are not in the interest of consumers, and offer products which appeal to them but do not fully or optimally serve their needs.

While healthy competition would drive out bad options for consumers, because of consumers' irrational decision-making, markets fail to eliminate the bad options for consumers. Market forces left to themselves will often not work to reduce these mistakes, so interventions may be needed. ${ }^{11}$

The Effective Approaches to support the implementation of the High-level Principles ${ }^{12}$ developed by the G20/OECD Task Force on Financial Consumer Protection, and in particular Principle 10 on Competition recognises that: "Insights provided by behavioural economics enhance understanding on how consumers make financial decisions and the inhibitors to competitive outcomes. Behavioural economics can assist in the design of more appropriate remedies, thus allowing more effective promotion of competition in financial markets". This was introduced as part of the innovative or emerging approaches to implement Principle 10.

In Australia for example, the principles of behavioural economics have been used to design a market intervention in relation to searching and comparing through the introduction of the key fact

${ }^{11}$ It is supposed though, that in specific circumstances, more competition may not improve (even worsen) consumer welfare: when consumers have a limited ability to compare competing products and the number of firm increases, then firms may be more likely to further complicate market comparisons, instead of lowering their prices (ACM, 2013)

${ }^{12}$ www.oecd.org/daf/fin/financial-education/G20-OECD-Financial-Consumer-Protection-PrinciplesImplementation-2014.pdf 
sheet for home loans. Behavioural economics research was used to identify the nature of the difficulties that consumers have in understanding pre-contractual documentation in relation to home loans and how disclosure could be improved. Research also indicates that the quantity of information can overwhelm consumers, which can encourage consumers to ignore pre-contractual disclosure information. In France, behavioural analysis helped to develop thinking about credit insurance, which led to a proposal to extend the period of time during which individuals can change their credit insurance, and has more generally helped to enrich thinking on the issues linked to the ability to terminate insurance contracts. ${ }^{13}$

Behavioural economics can therefore also play a critical role in improving the demand side of the financial services market, by ensuring that consumer choices of services and products are made on the basis of objective criteria which fulfil their specific needs. It will support well-functioning financial services markets and contribute to the development of effective competition for the benefits of both consumers and financial services providers.

\section{b) Behavioural economics core concepts relevant for financial services}

As a result of the research and studies conducted so far, there exists a set of core behavioural insights that are relevant to furthering our understanding of consumer decision making in financial markets. It consists mainly of categories of the most commonly encountered behavioural biases and types of mitigation responses which have proven effective in reducing the negative effects of biases. The following list is intended as a brief description of these essential, and largely uncontroversial, results and concepts with a view to facilitating an initial understanding of the behavioural economics approach and its relevance to financial services. It is neither an exhaustive list nor as a specific classification of biases or of mitigation responses. ${ }^{14}$

Types of bias

- Heuristics - Heuristics is a quick, informal and intuitive shortcut used to generate an approximate answer to a reasoning question. They are most often helpful, because they help solve a complex problem. However, if an inappropriate heuristics fails to produce a correct judgment (rule of thumb), it can result in a (cognitive) bias.

- Example: allocating the pension pot equally across all investment funds available in a pension scheme rather than making a careful allocation decision.

- Present bias - People tend to have preferences for immediate gratification. This leads them to overvalue the present over the future, and systematically choose options which will bring short-term benefits even though they are not the best value offers in the long-term.

- Example: over-borrowing, e.g. buying a tablet-PC now using a payday loan without thinking much about the total cost.

\footnotetext{
${ }^{13}$ www.oecd.org/daf/fin/financial-education/G20-OECD-Financial-Consumer-Protection-PrinciplesImplementation-2014.pdf, Principle 10

${ }^{14}$ Academics and researchers have adopted various ways of grouping and classifying biases and mitigation responses. The present list is largely based on the approach taken by the FCA (FCA, 2013)
} 
- Reference dependence (or anchoring effect) and loss aversion - Consumers assess outcomes relative to a reference point and not in their own right. Their choice can be instable as it will depend on the selected reference point. Gains and losses in particular are assessed according to a reference point, and the same outcome can be framed as a gain or as a loss depending on the choice of reference point. In all situations, people tend to underweight gains and overweight losses.

- Example: perceiving add-on insurance as cheap because it is sold together with something that has a comparatively much higher price.

- Regret and other emotions - People may act to avoid ambiguity or stress. Their choices can also be distorted by temporary strong emotions (e.g. fear).

- Example: buying expensive insurance for peace of mind, even though buyers are very unlikely to need it.

- Overconfidence - People tend to have excessive confidence in their own ability to successfully perform a particular task or to make an accurate judgement, or in the likelihood of good events.

- Example: excessive belief in the ability to pick winning stocks.

- Over-extrapolation - People often make predictions on the basis of only a few observations, when these observations are not representative.

- Example: using just a few years of past returns as a basis for judging future returns and making investment decisions, without considering the extent to which past returns reflect chance and particular circumstances.

- Projection bias - People have a tendency to believe that their choices and preferences will remain the same over time, and that there is only little room for change.

- Example: tying up funds in long-term contracts without adequately considering the chance of needing money in difficult circumstances before the contract matures, or not realising that difficulties could arise in controlling the future credit card spending.

- Mental accounting - Mental accounting describes how consumers tend to label money according to how they intend to use it, and behave differently with their different types of "accounts".

- Example: people may save at a low rate while borrowing at a high rate.

- Narrow bracketing - Narrow bracketing refers to the fact that people often take decisions in isolation, without giving consideration to their global (financial) context and risk exposure.

- Example: making investment decisions asset-by-asset rather than considering the whole portfolio.

- Persuasion and social influence - Consumers may allow themselves to be persuaded or trust the sales person because he or she comes across as 'likeable' and therefore trustworthy. 
Emphasising good personality traits or overemphasising bad personality traits may substitute for a reasoned judgement.

- Example: relying on financial advice without giving thought to the effect of commission or other economic incentives for the adviser on the advice received.

- Endowment effect - The endowment effect (or status quo bias) is the fact that people often demand much more to give up an object than they would be willing to pay to acquire it.

- Example: consumers refusing or being reluctant to switch financial provider or bank, although they know that the product or service provided is not tailored to their specific needs.

\section{Types of mitigation responses to bias}

Choice architecture and framing - The concept of choice architecture was introduced by Thaler and Sunstein (2008) and refers to the decision-making environment where many features, noticed and unnoticed, can influence decisions. Choice architecture can be used to help individuals make better choices (as judged by decision-makers themselves) without forcing certain outcomes upon anyone ("libertarian paternalism"). The number of choices presented, the manner in which attributes are described, the presence of a "default" option are amongst the elements with can impact choices. This approach seeks to design an environment in which better choice for consumers can be made to be the easier choice. Framing is part of the overall concept of choice architecture and describes how people tend to reach different conclusions or make different choices depending on how a situation or options are presented to them. Framing includes multiple aspects:

- Default option - Presenting one choice as a default or pre-set option can induce consumers to choose that option, as a way to avoid the costs of making a decision, or assuming that whoever set the default knew more about what is the right decision to make.

- Example: automatic enrolment of employees in pension schemes through a pre-selected option.

- Attribute framing - Attribute framing involves influencing people's judgment of an object or event by describing it in a positive or a negative manner, while its objective value remains constant. The object or event will be evaluated more favourably when presented in a positive frame than when presented more negatively.

- Example: informing consumers that they will pay a 3000 EUR up-front charge as opposed to 3\% when deciding whether or not to invest 100000 EUR into an investment product.

- Salience effect - The salience effect will focus consumers' attention on the particularly important aspects of a situation, which can then have a marked influence on choice. Even if information is standardised, a limited amount of simple text, meaningful numbers prominently displayed and in the right order can have a large effect when consumers compare options.

- Example: limiting the information provided to the most important features of a given financial product perceived as complex (e.g. mortgage or consumer credit), and providing pre-calculated and directly comparable relevant information. 


\section{Research methods}

As briefly outlined above (see section B.a.), behavioural economics research often makes use of randomised controlled trials, which can either be performed in a laboratory, in which participants are placed in a simulated environment where all factors affecting decision makers in a given situation can be fully controlled, or in a real-life environment through a field experiment. The researcher can in general draw statistically significant results from relatively small samples. RCTs involve two groups, the control group and the treatment group. Individuals or groups of people receiving both interventions are chosen at random and are as closely matched as possible. The control group receives the equivalent of a placebo (i.e. nothing is changed substantially), while the treatment group faces something new. Often researchers will want to know which of two or more interventions is the most effective at attaining a specific, measurable outcome. Running tests with as many treatment groups as there are researched options will lead to the identification of causal relationships. It will also help confirm that the envisaged intervention is the best suited to solve the problem identified and that robust measures are in place to evaluate the effectiveness of the intervention (UK Cabinet Office Behavioural Insights Team, 2012).

\section{Box 2. PRICE Lab: an experiment on how consumers value and compare complex products in Ireland}

Since January 2013, the Central Bank of Ireland has become involved in a three-year multi-partner research programme initiative which tests how consumers value and compare complex products. This initiative, established by the Economic and Social Research Institute (ESRI) Programme of Research Investigating Consumer Evaluation (PRICE) Lab, is jointly funded by the Central Bank, the Competition and Consumer Protection Commission (merger of the former National Consumer Agency and Competition Authority), the Commission for Energy Regulation and Commission for Communications Regulation. The programme is overseen by a Steering Group comprising representatives of each of the four funding partners, an independent international academic expert, a senior representative from the ESRI and the Principal Investigator.

PRICE Lab is using computerised experiments (using hypothetical products) to investigate how samples of Irish consumers initially learn to value a new product (using varied types and numbers of attributes, which give it an overall value). It repeated the experiments using real products (including financial and other products) in 2015. The aim of the research is to provide empirical findings of use to policymakers in the areas of consumer and competition policy.

\section{Applications in the financial services field}

Behavioural economics is of relevance across a range of financial sectors and activities (banking, investment, pensions, insurance, securities, etc.). Sectoral initiatives have also been taken to analyse particular consumer traits in a given field and explore potential behavioural remedies, for example in the specific context of financial education. A number of jurisdictions and agencies which are members of the Task Force on Financial Consumer Protection have conducted behavioural economics research in the field of financial services, developed policy papers or initiated policy or regulatory work based on behavioural insights.

This section reviews recent work undertaken by financial regulators, which has either been recorded and/or published, highlighting the main results and lessons learnt. 
The different initiatives are presented under three generic and broad categories of biases. ${ }^{15}$ Since decision-making is generally influenced by a combination of various factors, many of the examples could however fall under more than one category.

It is important to keep in mind that many of the current behavioural insights are prospective at this stage. The few regulatory or policy initiatives that are explicitly based on behavioural economic findings are fairly new. There is not yet any evidence about their long-term impact, and they have not yet been properly evaluated following implementation.

\section{Impediments to effectively using information}

The European Commission conducted a pilot study on consumer decision-making in retail investment services in 2010 to observe through laboratory experiments how consumers reacted when faced with a choice between different investment products and how they were affected by financial advice. $^{16}$

The study found that people struggled to make optimal investment choices even in the most simplified of environments. It also confirmed that features of the retail investment market may make consumer decisions particularly prone to biases and framing effects: subjects made worse investment decisions when the optimal choice was harder to understand (fees framed as percentages, annual returns not compounded over the duration of the investment), and they were disproportionately averse to uncertainty (risky investments), ambiguity (incomplete information) and product complexity (structured products). Standardising and reducing the amount of information provided helped subjects identify the optimal choice between similar investments. Providing comparable pre-calculated information on the net expected value of each investment helped subjects identify the optimal choice between dissimilar investments.

The European Commission used the results of this study as part of its proposals to regulate the sale of Packaged Retail and Insurance-based Investment Products (PRIIPS). ${ }^{17}$ The provision of a "Key Information Document" (KID) to all potential buyers of investment products is part of the 2012 proposal for regulation. This KID will present short and plain-speaking information about the investment product in a format easy to understand. Every manufacturer of investment products (e.g. investment fund managers, insurers, banks) will have to produce such a document for each investment product. Each KID will contain information on the product's main features, as well as the risks and costs associated with the investment in that product. Information on risks will be as straight-forward and comparable as possible, without over-simplifying often complex products. The KID will make clear to every consumer whether or not they could lose money with a certain product and how complex the product is. The KIDs will follow a common standard for the structure, content, and presentation. It is intended that in this way, consumers will be able to use the document to compare different investment products and ultimately choose the product that best suits their needs.

\footnotetext{
15 On the basis of the approach taken by New Zealand in Financial Product Disclosure: Insights from Behavioural Economics

${ }^{16}$ Consumer Decision-Making in Retail Investment Services: A Behavioural Economics Perspective European Commission, 2010

${ }^{17}$ Regulation (EU) No 1286/2014 of the European Parliament and of the Council of 26 November 2014 on key information documents for packaged retail and insurance-based investment products (PRIIPs)
} 
To ensure that the detailed rules on presenting the information in KIDs under the PRIIPS Regulation achieve the objective to best help consumers compare and select products for their investment needs, the European Commission has conducted a further dedicated consumer testing study. ${ }^{18}$ The study used broad quantitative surveys supplemented by qualitative testing with focus groups, across a representative sample of countries in the EU. The objective was not only to gather consumer's preferences, but also objective insights on how far presentations aided a correct understanding of the feature of PRIIPs and comparisons between them. To do this, many different options for presenting risk, performance and cost information were examined.

The study showed that a graphic and streamlined presentation of risks using a single scale with classes running from one to seven worked best. It also supported simpler presentations of performance and costs information, including the use of tables. The testing clarified that while some respondents expressed a preference for seeing detailed information, simpler information was in reality more effective for understanding and comparisons.

The study results will feed directly into the work by the three European Supervisory Authorities ${ }^{19}$ on developing technical standards to set the further specifications of the details of the format and content of the KID that they are elaborating. The study will ensure that European Consumers will benefit from being provided KIDs that will explain the often complicated investment products in a truly user-friendly way.

Regarding advised retail investment decisions and the disclosure of potential conflicts of interest, the 2010 experiment showed in particular that the existence of a conflict of interest in the remit of the advisor needs to be strongly emphasised ("health warning") and its implications explicitly laid out (for example, through the exact details of the advisor's remuneration structure), in order to impact people's decisions. Disclosing conflicts of interest elicited a "knee-jerk" reaction when biased incentives were disclosed. This led to better decisions when the advisor's and advisee's interests were adversely aligned but worse decisions when their interests were aligned. Subjects lost trust even when an advisor with misaligned incentives was not actually able to deceive them, showing that their reaction is reflexive. The European Commission indicates that the provision of the new Regulation on better disclosures about the features, risks and costs of products through the KID, and the overall improved transparency of the investments themselves, will help enhance the quality and neutrality of advice ${ }^{20}$.

The Central Bank of Ireland conducted a review into the provision of annual statements to consumers by life assurance firms, outlining the position of their investment product ${ }^{21}$. The purpose was to establish how life assurance firms were complying with the new annual format required by the 2012 Consumer Protection Code, for personal pension products. The review covered the 10 largest life assurance firms in Ireland. Overall, the Central Bank found that the vast majority of firms were in compliance, but also identified a small number of examples of firms failing to produce new format statements for pension policies. Where this was identified, firms were required to submit

\footnotetext{
${ }^{18}$ Consumer testing study of the possible new format and content for retail disclosures of packaged retail and insurance-based investment products: http://ec.europa.eu/finance/finservicesretail/investment_products/index_en.htm\#2015-consumer-testing-study

19 The European Banking Authority (EBA); the European Securities and Markets Authority (ESMA); and the European Insurance and Occupational Pensions Authority (EIOPA)

${ }^{20}$ The PRIIPS Regulation introducing the KID will become applicable as of 31 December 2016.

${ }^{21}$ Review of Annual Personal Pension Statements, Central Bank of Ireland, 2014
} 
implementation timelines for full compliance and commit to ensuring that all personal pension plan consumers, regardless of when the policy was sold, would receive a new format annual statement.

The Central Bank also asked consumers, via focus groups, to identify what was working well in terms of disclosure and where improvements to the annual statements could be made. Consumers in the focus groups said that the following would be of benefit:

- the use of "plain English" and clear distinct headings in the presentation of the statement

- details of the projected retirement income expressed as a monetary value, with information on what they could expect to get from their pension product when they retired

- information on the investment funds, including risk and the type of fund to be clearly highlighted on the statement including the location of the investments (for example, one firm provided clear details of the different funds that the consumer's policy was invested in, including the percentage breakdown of the investments under a separate heading titled "Investment Details")

- historical information on the performance of the policy (for example, one firm provided a statement with numerical information across the full duration of the pension policy)

- an indication on the annual statement of contribution gaps for the previous 12 months, as opposed to the current practice which includes these notifications in separate communications

- a link to a pension calculator so consumers can see whether they will have enough money built up in their fund for when they retire

- charges to be broken down into a euro value in the annual statement, and for all fees and charges to be provided in one location with a monetary total

- an indication regarding consumers' eligibility for state pension.

The findings from the focus group discussions were communicated to the life insurance firms reviewed, with an invitation to consider them in their communication with their personal pension plan and other investment customers.

In 2015, the UK Financial Conduct Authority (FCA) undertook a survey to investigate how well consumers understand and value structured deposits, a class of complex products. ${ }^{22}$ The FCA conducted a behavioural experiment involving more than 380 retail investors who had previously bought or would consider buying structured deposits or other structured products. Investors were shown hypothetical examples of five popular types of products with returns linked to the performance of the FTSE100 stock index. Investors' expectations about FTSE100 returns were compared with the returns they expected from different structured products. Biases in how respondents evaluate the structured deposits relative to the index could then be calculated. Investors were asked to rank the structured deposits against a range of fixed rate deposits and taking into account the risk of return of

\footnotetext{
${ }^{22}$ Two plus two makes five? Survey evidence that investors overvalue structured deposits, Financial Conduct Authority (FCA) UK, 2015
} 
the different structured deposits. The impact of various types of disclosure on respondents' valuations was also examined.

The main findings of the experience showed that:

- While investors' expectations of the FTSE growth were on average well aligned with the assumptions of the model, investors significantly overestimated the expected returns of all structured deposits, including the most simple. Their expectations were also significantly higher than returns from the quantitative model.

- Although all five structured deposits would have been unlikely to return more than simple fixed-term cash deposits, respondents did not recognise this. Investors required relatively high rates of return on risk-free cash deposits to value them over and above structured deposits.

- The disclosure of likely product returns and risk had some effect on investors' ability to adjust for initial incorrect valuations. Investors who had initially overestimated returns or underestimated risk of return were more likely to adjust their valuations following further information.

- Giving the investors information on what would happen under hypothetical scenarios had little effect on product revaluation, while quantitative model returns - telling investors what likely product returns are based on the quantitative model - induced a larger devaluation of structured deposits. The relatively minor adjustment of valuations by investors $(0.41 \%)$ shows the need to be cautious about what can be achieved through providing information.

In New Zealand, research on behavioural economics identified the main implications for the development of policy for financial product disclosure, with a focus on investment products. ${ }^{23}$ The conclusions from this work were that disclosures are most effective at aiding investor decision making when they are:

- Short and simple - research highlights the importance of keeping disclosure documents brief and straightforward to address issues of choice and information overload and the difficulties that many investors can have with complex and technical information.

- Standardised - many biases, limitations and heuristics can be mitigated through standardising the content of disclosures. Standardisation also aids the comparability of information.

- Clear about risks and benefits - disclosure of risk is necessary to address potential issues of overconfidence and appropriate disclosure of benefits is necessary to overcome status quo bias and loss aversion.

- Meaningful - information needs to be put in context and presented in a way that is meaningful for investors. The more that information can be put in a form that people relate to, the more likely they are to understand it.

\footnotetext{
${ }^{23}$ Financial Product Disclosure: Insights from Behavioural Economics, Ministry of Business, Innovation and Employment New Zealand, 2015
} 
- Well presented - information needs to be presented in a way that makes people want to read disclosure documents and that aids decision making. How options or prospects are framed in disclosure documents can elicit emotional responses and influence the decisions made. The use of graphs and other visual representations can assist in the understanding of complex information, but need to be designed with care.

- Tested on investors - research indicates that people can act in unexpected ways. Even small changes to the way that information is presented can influence how people perceive or interpret information.

The report also highlights that it is important that key behavioural insights are seen in the broader context of what a disclosure regime seeks to achieve (for example, a short and succinct document is not an end in itself if it fails to convey the necessary information), in order to effectively aid investors' understanding and decision making.

In terms of investor education, the International Organisation of Securities Commissions (IOSCO) has identified practices to help guide members in developing and enhancing their own investor education and financial literacy programmes. ${ }^{24}$ The report includes, in particular:

- A list of behavioural responses in financial decision-making that have important implications for the design of investor education and financial literacy strategies (Appendix 2).

- A behavioural economics literature review with a specific focus on financial education (Appendix 3).

\section{Influences on behaviour and perception}

In Italy, the financial regulator Consob reviewed questionnaires used by 20 investment firms to assess their potential clients' risk attitude before proposing an investment product. The objective was to identify major shortcomings, based, in particular, on behavioural insights, and suggest improvements. ${ }^{25}$

The study concludes that several limitations affect the content of the questionnaires used, in particular:

- Questions used to assess customers' investment knowledge and experience are poor: they often rely on individuals' self-evaluation and are not aimed at verifying familiarity with basic notions like the relationship between risk and expected return and portfolio diversification.

- Consumers' risk attitude is generally elicited jointly with preferences on the time horizon and investment aims. This format has been criticised, in particular by behavioural economists, because risk preferences and the risk profile should be assessed independently from the other elements which must be gathered when formulating an investment recommendation, since each of these variables is influenced by different factors (for example, risk preferences and risk profile are attributable to sociometric, psychological and behavioural factors, while the

\footnotetext{
${ }^{24}$ Strategic framework for investor education and financial literacy, IOSCO, CR03/14, 2014

${ }^{25}$ Assessing investors' risk tolerance through a questionnaire, Consob Italy, 2012
} 
time horizon and investment objectives depend on economic and financial factors, the level of impatience, etc.).

- The way questions on risk attitude are worded lacks the stylistic and lexical devices which, according to behavioural finance, may be useful in enhancing the reliability of the answers potentially affected by the client's cognitive and behavioural biases.

An example of a behavioural experiment undertaken by the FCA UK formed part of its market study on general insurance products commonly sold as add-ons, i.e. general insurance sold alongside other (primary) products either at the same time or subsequently, like travel insurance sold alongside a holiday. ${ }^{26}$

The study investigated whether there were common patterns across add-on markets that weakened competition and drove poor consumer outcomes. As part of the experiment, variations were introduced on the sales and price formats and the point at which add-ons were proposed (standalone insurance, add-on upfront alongside the primary product, add-on revealed only at point of sale for the primary product). This helped identify the effects on the extent and effectiveness of shopping around and on the add-on take up.

Amongst the main findings of the study:

- The complexity of comparing multiple prices (of the primary and the add-on products) at the same time without a clear total did not discourage consumers from shopping around for insurance, although it made them slightly less willing to look at primary product alternatives. However, added complexity - even without delaying the introduction of the add-on until the point of sale - made consumers much more likely to be unable to identify the best deals available to them.

- Lower transparency due to add-ons being revealed only at the point of sale significantly exacerbates poor consumer outcomes. This element of the add-on mechanism was the most consistent in producing material detrimental effects on the outcome metrics studied in the experiment - including shopping around, prices paid and the quality of consumers' decisions.

- Monthly pricing for annual contracts was another mechanism that had consistent, if smaller, detrimental effects across most types of outcomes. Surprisingly, however, even though presenting prices in monthly terms reduced the extent and effectiveness of shopping around, the fact that insurance 'looked cheaper' did not have an effect on consumers' willingness to buy it overall.

- Consumers are, in principle, willing to engage with stand-alone alternatives when those are easy to access at the point of sale, and benefit considerably from doing this. However, the beneficial effects start to diminish quickly when there are barriers to accessing those alternatives, even if these barriers are much smaller than the ones consumers face in real life.

Overall, the FCA UK concluded that the add-on mechanism weakens consumers' ability to discipline firms by shopping around and comparing products effectively. Areas which are being

\footnotetext{
${ }^{26}$ How does selling insurance as an add-on affect consumer decisions? A practical application of behavioural experiments in financial regulation, FCA UK, 2014
} 
looked at for remedies include: a ban on pre-ticked boxes to challenge consumer inertia, publication of claims ratios to reduce information asymmetries, and improvements to the way add-ons are offered through price-comparison sites.

In Australia, the Australian Securities and Investment Commission (ASIC) embarked on a laboratory experiment which aimed at exploring how behavioural biases may influence preferences towards hybrid securities over the less complex financial products of bonds and shares. ${ }^{27}$ Participants were asked to invest 100 units between three investment options for 10 years, and were informed that they would be paid on the outcome of their investment. In each of the experiments, the government bond option was provided as a default low risk option and 5 out of the 6 possible choices also offered company shares. The expected interest rate/dividend between three options was altered $(3.75 \%$, $4.75 \%$, and $5.75 \%$ per annum). Findings show that the behavioural biases and risk attitudes that influence investment in hybrid securities include:

- the illusion of control that investors can exert over their environment and influence the outcomes. In the context of hybrid securities, it meant that consumers believed they could withdraw "in time" from their investment.

- investors' overconfidence on their ability to withdraw from an investment early and consequently be protected from risks

- a framing bias regarding the formulation of the choice in favour of hybrid securities. Many of the risks of hybrid securities are not immediately apparent, which makes the risk/return tradeoff more appealing than shares and bonds

- "ambiguity aversion" or a preference of known risks over unknown risks. Ambiguity averse participants preferred "higher yet familiar" risk of investing in shares to "lower but less understood" risk of investing in hybrids.

- investors' risk perception and attitudes. Hybrids were seen to be riskier than shares and bonds on two counts: distrust of issuers/products and poor knowledge of the product. However, acknowledging the difficulty in understanding hybrid securities did not deter participants from buying them.

The familiarity of the brand of issuers did not affect investment in hybrids, which may indicate that where information is provided in a succinct and standardised manner, the effect of a brand name may be negligible.

\section{Presentation factors that affect decision-making}

The FCA UK has conducted a research on how to encourage consumers to claim redress following the mis-selling of financial products. ${ }^{28}$ Work was conducted on a real case, with a firm that voluntarily wrote to almost 200000 customers about a failing of its sales process. Mis-sold customers needed to answer questions raised in the letter to get redress. The firm's original letter, written in good faith, had a very low response rate. Different potential improvements to the firm's letter were tested

\footnotetext{
27 Investing in hybrid securities: explanations based on behavioural economics, Australian Securities and Investment Commission (ASIC), 2015

${ }^{28}$ Encouraging consumers to claim redress: evidence from a field trial, FCA, 2013
} 
using an RCT, with a view to increasing the level of customers' response. The letter was modified with simple amendments, including reducing the amount of text, explaining to readers that the claims' process would only take five minutes, putting the main thrust of the message in bullets at the top of the letter, adding an "act quickly" label on the envelope and the FSA logo on the letter and replacing the generic "Customer Team" signature by the CEO's. Reminders were also sent.

Overall, the rate of responses jumped by over $10 \%$. Individually:

- Salient bullets had the largest single effect.

- Simplification and claims process almost doubled the response rate.

- The label on the envelope had only a small positive effect.

- There was no impact of the FSA logo.

- The reminder had clear interaction effects.

Unexpectedly, there was a small but statistically significant decrease in response using the CEO's signature.

The FCA has undertaken an analysis of holders of savings accounts with short-term high interest rates who do not transfer their money when the rate falls because of behavioural biases, such as undervaluing long-term gains relative to short-term costs (present bias) or paying insufficient attention to their savings choices (limited attention) ${ }^{29}$ The FCA has carried out a trial in partnership with a large UK financial institution involving over 20000 savings account customers whose interest rate was about to decrease or had just decreased. All of these customers had already received a letter two to three months before the rate decrease informing them of this. The paper investigates the effects on switching behaviour of an additional letter, different messages in the reminder and the timing of the reminder.

Results show that:

- Reminders make a notable difference to switching behaviour around the time of interest rate decreases. The very fact of getting a reminder is more important than the precise phrasing of the reminder.

- Customers who received a reminder in which the cash loss from not switching accounts was salient (i.e. ' $£ X$ less interest per year') or in which the cash gain was salient (i.e. 'Move your savings and earn up to £X more'), among other changes, were slightly more likely to switch or transfer money than those who received a reminder without any particular emphasis.

- Sending a reminder letter before the interest rate decrease increased switching compared with not sending a reminder. While switching to a comparable account within the firm decreased, moving money elsewhere - switching to a different firm or other behaviour - increased.

- Sending a reminder after the rate decrease also led to more switching compared with not sending a reminder, but only by encouraging customers to open a new comparable account with the same firm. It had no detectable effect on switching or transferring elsewhere.

\footnotetext{
${ }^{29}$ Stimulating interest: Reminding savers to act when rates decrease, FCA, 2015
} 
- While customers over 60 years old or with balances above the median were more likely to switch in general, reminders increased the rate of switching across all customers including younger customers and those with lower balances.

In the context of a potential Competition and Markets Authority investigation into personal current accounts, the FCA in 2015 wanted to understand the impact of previous initiatives that were intended to help consumers manage their current accounts - provision of annual summaries of any charges, refunds or interest, access to text alerts on account balance levels and charges, as well as to mobile apps which allow consumers to spend, save and check their balances on-the-go. ${ }^{30}$

\footnotetext{
${ }^{30}$ Message received? The impact of annual summaries, text alerts and mobile apps on consumer banking behaviour, FCA, 2015
} 
Using statistical analysis of data from two large banks, including granular data on 500000 customers from one bank, the study shows that:

- Annual summaries, as designed by the banks looked at, have no effect on consumer behaviour in terms of incurring overdraft charges, altering balance levels or switching to other current account providers.

- Signing up to text alerts or mobile banking apps reduces the amount of unarranged overdraft charges incurred.

- Signing up to both services has an additional effect, and shows the benefit of receiving information upon automatic triggers, without having to actively acquire it, as well as the facility to act quickly upon receiving information. Text alerts and mobile banking apps also decrease average current account balances, which is beneficial for consumers as they reduce the cost of holding balances in accounts with no (or low) credit interest. Consumers who sign up to these services are also more likely to become inactive at their bank, which is measured using the number and value of consumers' credits and debits per month. This suggests that these services facilitate banking with multiple providers.

\section{E. Application in developing economies}

The application of behavioural insights in emerging markets and developing economies is especially important, due to the nature of both the financial markets of those countries (e.g. fast pace of innovation) and many of their financial consumers (large part of first time users of formal finance, impact of having a low and variable income). Studies conducted so far identify the areas which are most affected by consumers' biases and could require some policy interventions. They also confirm (see footnote 5) that financial institutions and bank staff can be biased, and this will potentially impact the service provided to consumers.

In 2014, the Consultative Group to Assist the Poor (CGAP) produced a paper focused on emerging markets and developing economies and presents early evidence on some of the most relevant behavioural insights in those markets with high concentration of base-of-the-pyramid (BOP) consumers. ${ }^{31}$ The paper explores how behavioural research can offer important tools for effective policy-making.

Four priority consumer protection topics with specific implications in BOP settings were reviewed: disclosure, transparency, and product choice; complaints handling and recourse; credit market regulation and debt stress; and fair treatment.

CGAP notes that knowledge and experience on which approaches will work best to protect financial consumers is very limited at this time. However, evidence suggests the power of several key behavioural concepts to improve outcomes:

- Scarcity - Many cognitive biases tend to be widespread and do not align neatly with the socioeconomic context. However, there is a need to generate and apply insights into the role scarcity plays in financial and other decisions taken by many BOP consumers, and design policies that factor in its effects.

\footnotetext{
${ }^{31}$ Applying behavioral insights in consumer protection policy, CGAP, 2014
} 
- Improved information for consumer choice and use - Increasing the volume of information provided to consumers is not always the best way to facilitate decision-making and understanding. Two alternatives should be considered: putting in place measures such as default options that nudge consumer behaviour and improve outcomes, and simplifying the information available to consumers and/or choices that would improve the effectiveness of consumers' comparison, selection, and use of financial products.

- Salience - Financial information should be made more relevant to a consumer's personal context to improve their understanding and decision-making. Connections to different points in a consumer's daily activities or lifecycle events can make information more meaningful, increase their receptivity to the messages, and bring greater changes in their behaviour.

- The intention-action gap - Research should be undertaken to understand how contextual issues - both perceived and subconscious - contribute to gaps in individuals' preferences and decisions and the behaviours they exhibit. This analysis should be used to design policy measures that tackle the underlying issues.

- Drivers of provider behaviour - Factors that affect the behaviour of financial service providers and their staff, which may in turn reflect a complicated mix of short-term incentives as well as their perceptions of consumers should be explored. This would help design policy measures that shift providers' behaviour and incentives and produce better long-run outcomes for consumers (and often for providers, too).

The CGAP paper clarifies that it only offers some starting hypotheses on how behavioural biases may shape consumer protection problems and potential solutions, while stressing the importance of sourcing and applying insights specific to each market and key consumer segments within those markets. It adds that it is critical to increase experimentation with behaviourally informed consumer protection policy-making in emerging markets and developing economies, and to build better tools and a stronger evidence base.

\section{F. Opportunities and challenges for the application of behavioural insights in the field of financial services}

\section{Key elements for an optimal application of a behavioural approach in the field of financial services}

Efficient application of a behavioural economics approach to financial services requires that regulators and policy-makers have an extensive knowledge of the main biases leading consumers to make mistakes of judgement and that they are able to identify the products/services causing the main problems. They must also define the most appropriate response to the problems identified. A behavioural approach will only bring possible solutions to problems caused by the psychological aspects of the decision-making process of consumers. It is not intended to solve problems it is not meant to address.

Behaviourally-inspired solutions should therefore be used as complements, not as alternatives, to existing initiatives. They are an additional tool for policy-makers, regulators and supervisors, in order to make public interventions more flexible and less stringent, but more effective (FCA, 2013). The asymmetry of information between financial institutions or intermediaries and consumers still needs to be addressed and it is important that strict requirements are imposed to financial services providers. But it was evidenced that the mandatory disclosure of extensive information, by itself, cannot cater for the various needs of consumers. The extent, the format, the point at which the information has to be 
delivered, and the moment when it needs to reach the consumer also need to be carefully considered, possibly through tools using nudges and other framing effects.

Behavioural economics should be integrated into the broader context of the policy/regulatory analysis, and the overall impact of the set of measures has to be assessed, with particular regard to their likely effectiveness in the long-term and their impact on innovation. The other (structural or systematic) problems of the market should also be considered, and the package of solutions/corrective measures in one field should not have any unintended negative effects on any other field (FCA, 2013).

\section{Challenges for regulators and policy-makers}

The results of behavioural economics studies and research are/have been (mis)used or utilised by firms, including financial institutions, to trigger or exacerbate consumers' biases. Product design, marketing techniques or sales processes sometimes build on consumers' misbeliefs and intuitive judgements and decision making to enhance sales and profits. There is a need to work with firms to demonstrate and convince them that "de-biasing" consumers is also in their best interests, as it will stimulate fair and open market competition (Van Bavel et al., 2013).

The "paternalistic" approach induced by behavioural economics has to be used with care, and in this respect, reservations on the whole behavioural economics approach have been expressed (for example Loewenstein and Hubel, 2010). Introducing a behavioural approach to regulation and policymaking raises fundamental questions for regulators and policy-makers: can they or should they decide or determine what is in consumers' best interests? To what extent and when can they advise consumers on what is good for them? To what extent would this approach respect consumers' freedom of choice and freedom to make mistakes? It seems that there are two limits. Firstly, that the consumer's errors have not occurred due to misleading or unfair practices of providers, and secondly that the sum of individual consumers' misbehaviours does not negatively affect the economy as a whole (financial crisis). Reasonable consumer choices should not be questioned and this supposes that what consumers really value is well known and understood.

There might be a need for principles and guidelines which the policy-makers and regulators should follow to better incorporate behavioural insights into their initiatives.

\section{G. Conclusions}

Financial decisions involve making difficult choices that often impact the wellbeing of consumers and of their families over the long-term. As many other choices made by human beings, those decisions are not always consistent and rational. Getting a better understanding of consumers' decision-making processes is therefore important to mitigate the influence of the behavioural biases known to (negatively) influence economic and financial decisions.

Behavioural economics research has shown that measures informed by consumers' biases and resulting behaviours can have a positive effect on the efficiency of the regulatory and policy framework.

As stated in the Effective approaches to support the implementation of the G20/OECD High Level Principles on Financial Consumer Protection, regulators and supervisors can use the insights gained through behavioural economics research to inform their approach to potential remedies to help consumers. 
The G20/OECD Task Force on Financial Consumer Protection supports the need for further work and analysis to explore the benefits and the challenges of adopting a behavioural economics approach to policy, regulation and supervision, with a view to improving the outcomes for the consumers of financial products and services.

The existing corpus of behavioural economics research shows that behaviourally-inspired policy and regulatory and supervisory responses have a positive effect on the efficiency and effectiveness of national consumer protection frameworks. A number of initiatives led by Task Force Members have confirmed the promising results of using behavioural economic insights to design specific interventions which can act as additional tools to more conventional "hard" legislative interventionist measures.

At this early stage of the implementation of behavioural economics solutions to financial consumer protection problems, there is a need to initiate an exchange of experiences and of good practices not only within the G20/OECD Task Force on Financial Consumer Protection but with a much wider audience of policy makers, regulators, supervisors and other stakeholders. Findings from further research projects, lessons learnt from the implementation of measures, as well as evidence about the long-term impact of these measures are specifically of mutual interest and should be shared in the future. 


\section{REFERENCES}

Amstrong M. and Huck S. (2010), Behavioural economics as applied to firms: a primer, Competition Policy International, Vol. 6, Number 1, Spring 2010, http://else.econ.ucl.ac.uk/papers/uploaded/359.pdf

Angner E. and Loewenstein G. (2006), Behavioural Economics, Handbook of the Philosophy of Science, Vol. 5, www.cmu.edu/dietrich/sds/docs/loewenstein/BehavioralEconomics.pdf

Arrow and Debreu (1954), Existence of an Equilibrium for a Competitive Economy, Econometrica 22 (3): $265-$ 290, www.jstor.org/stable/1907353?origin=crossref\&seq=1\#page_scan_tab_contentsAutoriteit

Camerer C.F. (1999), Behavioral economics: Reunifying psychology and economics, Proceedings of the National Academy of Sciences (PNAS), Vol. 96, pp. 10575-10577, September 1999, www.pnas.org/content/96/19/10575.full.pdf

Camerer C.F. and Loewenstein G. (2003), Behavioral Economics: Past, Present, Future in Advances in Behavioural Economics, Princeton University Press, www.andrew.cmu.edu/user/gl20/GeorgeLoewenstein/Papers_files/pdf/BehEconPastPresentFuture.pdf

Consument \& Markt (ACM)/The Netherlands Authority for Consumers and Markets (2013), Behavioural Economics and Competition Policy, www.acm.nl/en/publications/publication/11610/ACM-publishesstudy-into-behavioural-economics-and-competition-policy/

Cooper J.C. and Kovacic W.E. (2012), Behavioral economics: implications for regulatory behaviour - Journal of Regulatory Economics, February 2012, Volume 41, No. 1, pp 41-58, www.law.gmu.edu/assets/files/publications/working_papers/1313BehavioralEconomicsImplications.pdf

Dolan P., Dr Halpern D., King D., Vlaev I., Hallsworth M. (2010), MINDSPACE, Influencing behaviour through public policy, UK Cabinet Office/Institute for Government, www.instituteforgovernment.org.uk/sites/default/files/publications/MINDSPACE.pdf

Financial Conduct Authority (FCA) (2013) Applying behavioural economics at the Financial Conduct Authority, Occasional Paper 1, www.fca.org.uk/static/documents/occasional-papers/occasional-paper-1.pdf

Financial literacy and education Russian Trust Fund (2013), Improving financial education effectiveness through behavioural economics, OECD key findings and way forward, www.oecd.org/daf/fin/financialeducation/TrustFund2013 OECDImproving_Fin_Ed_effectiveness through_Behavioural_Economics.pdf

Hershfield H.E., Goldstein D.G., Sharpe W.F., Fox J., Yeykelis L., Carstensen L.L., Bailenson J.N. (2011), Increasing Savings Behavior Through Age-Progressed Renderings of the Future Self, Journal of Marketing Research, Vol. XLVIII (November 2011), S23-S37, www.dangoldstein.com/papers/Hershfield_Goldstein_et_al_Increasing_Saving_Behavior_Age_Progresse d_Renderings_Future_Self.pdf

Heukelom F. (2006), Kahneman and Tversky and the origin of behavioral economics, Tinbergen Institute Discussion Paper TI 2007-003/1, http://dieoff.org/ Economics/Origin\%20of\%20Behavioral\%20Economics07003.pdf

Kahneman D. and Tversky A. (1979), Prospect Theory: An analysis of decision under risk, Econometrica, Vol. 47, No. 2 (Mar., 1979), pp. 263-292 www.jstor.org/stable/1914185?seq=1\#page_scan tab_contents

Lunne P. (2014), Regulatory Policy and Behavioural Economics, OECD, DOI: http://dx.doi.org/10.1787/9789264207851-en 
Loewenstein G. and Hubel P. (2010), Economics Behaving Badly, OpEd Newx York Times, 14 July 2010, www.nytimes.com/2010/07/15/opinion/15loewenstein.html?_r=2

McAuley I. (2010), When does behavioural economics really matter? Australian Economic Forum, August 2010, www.home.netspeed.com.au/mcau/academic/confs/bepolicy.pdf

OECD (2007), Implications of behavioural economics for mandatory individual account pension systems, www.oecd.org/finance/private-pensions/39368306.pdf

OECD (2008), Improving financial education and awareness on insurance and private pensions, www.oecd.org/finance/financial-education/ improvingfinancialeducationandawarenessoninsuranceandprivatepensions.htm

OECD (2010), Consumer Policy toolkit, www.oecd.org/sti/consumer/consumer-policy-toolkit-9789264079663$\underline{\text { en.htm }}$

OECD (2017), Behavioural Insights and Public Policy: Lessons from Around the World, OECD Publishing, Paris. DOI: http://dx.doi.org/10.1787/9789264270480-en

Pareto V. (1935), The Mind and Society, Kessinger Pub Co.

Pettit A. (2014), Behavioral Economics: New or new to you? www.linkedin.com/pulse/201404241833366511942-behavioral-economics-new-or-new-to-you

Salmuelson (1947) Foundations of Economics Analysis

Simon H.A. (1957), Models of man, social and rational, Wiley (1st edition)

Smith A. (1790), The Theory of Moral Sentiments, www.econlib.org/library/Smith/smMS.html

Thaler R. and Sunstein C. (2003), Libertarian Paternalism, The American Economic Review 93: 175-179, http://econweb.ucsd.edu/ jandreon/Econ264/papers/Thaler\%20Sunstein\%20AER\%202003.pdf

Thaler R. and Sunstein C. (2008), Nudge: Improving Decisions About Health, Wealth, and Happiness, Yale University Press

UK Cabinet Office Behavioural Insights Team (2012), www.gov.uk/government/uploads/system/uploads/attachment_data/file/62529/TLA-1906126.pdf

Van Bavel R., Herrmann B., Esposito G., Proestakis A. (2013), Applying Behavioural Sciences to EU Policymaking, European Commission, Joint Research Centre Scientific and Policy reports, http://ftp.jrc.es/EURdoc/JRC83284.pdf 


\section{ANNEX: COMPILATION AND SUMMARY OF SELECTED KEY STUDIES, REPORTS AND ARTICLES ON BEHAVIOURAL ECONOMICS APPLIED TO FINANCIAL SERVICES}

\section{Academics and think tanks}

The Power of Suggestion: Inertia in 401(k) Participation and Savings Behavior - Brigitte C. Madrian and Dennis F. Shea, Quarterly Journal of Economics, 2001

The paper analyses the impact of automatic enrolment on the most common US types of employer-sponsored retirement savings plans, known as "401(k)". It highlights first that 401(k) participation is significantly higher under automatic enrolment. Second, a substantial fraction of 401(k) participants hired under automatic enrolment retain both the default contribution rate and fund allocation even though few employees hired before automatic enrolment picked this particular outcome. This "default" behaviour appears to result from participant inertia and from employee perceptions of the default as investment advice. These findings have implications for the design of 401(k) savings plans as well as for any type of Social Security reform that includes personal accounts over which individuals have control. They also shed light more generally on the importance of both economic and noneconomic (behavioural) factors in the determination of individual savings behaviour.

Libertarian Paternalism - Richard H. Thaler and Cass R. Sunstein, American Economic Review, 2003

The paper explores how it is both possible and legitimate for private and public institutions to affect individual's behaviour and decisions while also respecting their freedom of choice. Often people's preferences are ill-formed, and their choices will inevitably be influenced by default rules, framing effects, and starting points. In these circumstances, a form of paternalism cannot be avoided. The report argues that equipped with an understanding of behavioural findings of bounded rationality and bounded self-control, libertarian paternalists should attempt to steer people's choices in welfarepromoting directions without eliminating freedom of choice. It is also possible to show how a libertarian paternalist might select among the possible options and to assess how much choice to offer. The article gives examples from many areas, including savings behaviour, labour law, and consumer protection.

\section{Influence: The Psychology of Persuasion - Robert B. Cialdini, Revised Edition 2006}

The book explains the psychology of why people say "yes" and how to apply these understandings. The author has identified six principles of influence (also known as the six weapons of influence) through experimental studies, and by immersing himself in the world of what he called "compliance professionals" - salespeople, fund raisers, recruiters, advertisers, marketers etc. Those six principles are reciprocity; commitment (and consistency); social proof; liking; authority; and scarcity.

Why incoherent preferences do not justify paternalism - Robert Sugden, Constitutional Political Economy, 2008 
The report underlines that the arguments emerging from behavioural economics claim to undermine the credibility, and even the conceptual coherence, of the economist's traditional rejection of paternalism. Some suggest that the incoherent nature of individuals or consumers' preferences inevitably implies a form of paternalism. However, this conception would presuppose a "planner" with the responsibility to collate information about individuals' preferences and well-being and then, guided by that information, to promote the overall social good. The paper argues that, in this context, there is a viable alternative to paternalism: markets operate according to a system of economic organisation that is structured by mutual advantage, i.e. each transaction, considered in isolation, furthers the interests of everyone who is a party to it. This approach does not require consumers' preferences to be coherent.

Nudge: Improving Decisions about Health, Wealth, and Happiness - Richard H. Thaler and Cass R. Sunstein, Yale University Press, 2008

Human beings often make bad decisions involving education, personal finance, health care, mortgages and credit cards, the family, and the planet itself. They are susceptible to various biases that can lead them to blunder. The book takes humanness as a given and shows that by knowing how people think, choice environments can be designed that make it easier for people to choose what is best for themselves, their families, and their society. It demonstrates how thoughtful "choice architecture" can be established to nudge people in beneficial directions without restricting freedom of choice.

Behaviourally informed financial services regulation - Michael S. Barr, Sendhil Mullainathan and Eldar Shafir, Asset Building Programme/New America Foundation, 2008

The paper adopts a behavioural economic framework that considers firm incentives to respond to regulation. Under this framework, outcomes are an equilibrium interaction between individuals with specific psychologies and firms that respond to those psychologies within specific market contexts. Regulation must then address failures in this equilibrium. The model suggests, for example, that in some contexts market participants seek to overcome common human failings (as for example, with under-saving) while in other contexts market participants seek to exploit these failings (as for example, with over-borrowing). Behaviourally informed regulation needs to take account of these different contexts. The paper discusses the specific application of these forces to mortgage, credit card, and banking markets. The purpose of this paper is to illustrate how a behaviourally informed regulatory analysis would lead to a deeper understanding of the costs and benefits of specific policies.

Bank Herding and Incentive Systems as Catalysts for the Financial Crisis - Peter Haiss, IUP Journal of Behavioral Finance, 2010

Rooted in regulatory economics and behavioural finance, the paper offers a taxonomy of effects that narrows the scope of the banks' decision making into a funnel-shape and thus, prepares the ground for a financial crisis. The overall conclusion of the paper is that inconsistent decision rules, rigid bank regulations, stakeholder-focused incentive structures within banks and uncritical adoption of innovations may force banks into decisions that are micro-functional, but macro-dysfunctional. Behavioural aspects play a key role in the suggested remedies on the regulatory side (macroprudential regulation, supervision of incentives) and on the banking side (proper reward systems and structured decision making) to re-establish prudent banking. 
Behavioural economics as applied to firms: a primer - Mark Amstrong and Steffen Huck, Competition Policy International, 2010

The paper discusses the literatures on behavioural economics, bounded rationality, and experimental economics as they apply to firm behaviour in markets. In much of the behavioural economics studies, the assumption is that firms are fully rational and aim to maximize their profits. However, firms sometimes depart from the profit-maximizing objective, for various reasons discussed in the paper, such as the impact of imitative and "satisficing" (satisfying + sufficing) behaviour, outcomes when managers care about their position relative to peers, the employment of managers whose objective diverge from profit-maximization (including managers who are overconfident or base pricing decisions on sunk costs), the impact of social preferences on the ability to collude, and the incentive for profit-maximizing firms to mimic irrational behaviour.

Consumer Financial Protection - John Y. Campbell, Howell E. Jackson, Brigitte C. Madrian and Peter Tufano, Journal of Economic Perspectives, 2011

The recent financial crisis has led many to question how well businesses deliver services and how well regulatory institutions address problems in consumer financial markets. This paper discusses consumer financial regulation, emphasizing the full range of arguments for regulation that derive from market failure and from limited consumer rationality in financial decision making. Three case studies are presented - mortgage markets, payday lending, and financing retirement consumption - to illustrate the need for, and limits of, regulation. The paper argues that if regulation is to be beneficial, it must be tailored to specific problems and must be accompanied by research to measure the effectiveness of regulatory interventions.

Behavioral economics: implications for regulatory behaviour - James C. Cooper, George Mason University School of Law; William E. Kovacic, Journal of Regulatory Economics, 2012

This paper considers how biases affect regulatory decisions, in the case of a regulator who serves as an agent to a political overseer. The regulator chooses a policy that accounts for the rewards he/she receives from the political overseer - whose optimal policy is assumed to maximize short-run outputs that garner political support, rather than long-term welfare outcomes - and the weight the regulator puts on the optimal long run policy. Flawed heuristics and myopia are likely to lead regulators to adopt policies closer to the preferences of political overseers than they would otherwise. The incentive structure for regulators is likely to reward those who adopt politically expedient policies, either intentionally (due to a desire to please the political overseer) or accidentally (due to bounded rationality). The paper urges that careful thought be given to calls for greater state intervention, especially when those calls seek to correct firm biases. It proposes measures that focus rewards to regulators on outcomes rather than outputs as a way to help ameliorate regulatory biases.

Consumer Protection: Bounded Rationality and Regulation (La protection du consommateur : rationalité limitée et régulation) - Xavier Gabaix, Augustin Landier and David Thesmar, Conseil d'Analyse économique, 2012

This report examines the foundations for consumer protection and the regulatory procedures required to ensure such protection. In practice, the consumer does not necessarily behave in the ways supposed in microeconomic analysis of consumer guides. Imperfect information and bounded rationality cannot be managed or corrected by self-regulation alone. In many cases, intervention by the public authorities is essential. Such intervention takes the form of both ex ante regulations (prior definition of requirements and constraints) and ex post regulations (recourse under the law and sanctions, etc.). The report results in a number of proposals, some of which are aimed at making major 
improvements to information available to the consumer; others are related to ex post regulation. The report proposes more severe administrative fines (imposed by the Directorate General for Competition Policy, Consumer Affairs and Fraud Control, DGCCRF, part of the Ministry of Economy). It advocates the acknowledgement of class action in France.

Behavioral Economics and Behavior Change - David Laibson, Harvard University, presentation at the 2013 conference of the American Association for the Advancement of Science/European Commission Joint Research Centre

Behavioural economics explains why people often fail to act in their own best interest and are often influenced by the fact that costs come early and benefits come late. The presentation shows that this self-defeating behaviour can be changed using inexpensive, scalable interventions: defaults and other nudges/interventions have already made a big difference, for example for contributions to savings schemes. The author advises policymakers not to rely on doctrine or introspection, but to focus on data and small scale experiments. Finding answers to two key questions should help them drive the process: which behaviours would they like to influence, and how can they transform good intentions into long-lasting actions?

Learning in the Credit Card Market - Sumit Agarwal, John C. Driscoll, Xavier Gabaix and David Laibson, 2013

The paper measures learning dynamics using a panel with four million monthly credit card statements. It studies add-on fees, specifically cash advance, late payment, and over-limit fees. New credit card accounts generate fee payments of over USD 16 per month. Through negative feedback i.e. paying a fee - consumers learn to avoid triggering future fees. Paying a fee last month reduces the likelihood of paying a fee this month by about $40 \%$. Controlling for account fixed effects, monthly fee payments fall by $75 \%$ during the first three years of account life. We find that learning is not monotonic. Knowledge depreciates about $10 \%$ per month, implying that learning displays a strong recency effect.

The Nature of the Beast: What Behavioral Economics Is Not - Matthew Darling, Saugato Datta, and Sendhil Mullainathan, The Center for Global Development, 2013

The paper seeks to remove misconceptions about behavioural economics, and for this defines the concept by what it is not: behavioural economics is not about controlling behaviour, as behavioural tools are about helping people to make the choices that they themselves want to make; behavioural economics is not Liberal (or Conservative), as it has being picked up and used by a wide range of governments as well as private companies; behavioural economics is not about "irrationality" in the pejorative and condescending common meaning. The use of "irrationality" stems from a simplification of the field's experimental findings that distinguish real-world human behaviour from the predictions of traditional economic theory.

Protecting Consumers from Add-On Insurance Products: New Lessons for Insurance Regulation from Behavioral Economics - Tom Baker, Peter Siegelman, Connecticut Insurance Law Journal, 2013

Persistently high profits on "insurance" for small value losses sold as an add-on to other products or services (such as extended warranties sold with consumer electronics, or credit life insurance sold with a loan) pose a twofold challenge to the standard economic analysis of insurance. First, expected utility theory teaches that people should not buy insurance for small value losses. Second, the market should not in the long run permit sellers to charge prices that greatly exceed the cost of providing the 
insurance. Combining the insights of the shrouded pricing model with the behavioural economics of insurance, this paper explains why high profits for add-on insurance persist and describes the negative distributional and welfare consequences of an unregulated market for such insurance. Drawing on theoretical, empirical, and comparative law sources, the paper explains why enhanced disclosure will not work, the circumstances under which a point of sale ban of offer of add-on insurance is desirable, and why a new, on-line market is preferable to price regulation in circumstances in which a point of sale ban is undesirable.

\section{Regulators and policy-making bodies}

MINDSPACE, Influencing behaviour through public policy - Paul Dolan, Dr David Halpern, Dominic King, Ivo Vlaev, Michael Hallsworth, UK Cabinet Office/Institute for Government, 2010

The reports underlines how new insights from science and behaviour change could lead to significantly improved outcomes, and at a lower cost, than the way many conventional policy tools are used. It explores how behaviour change theory can help meet current policy challenges, such as how to reduce crime, tackle obesity and ensure environmental sustainability. Today's policy makers are in the business of influencing behaviour - they need to understand the effects their policies may be having. "MINDSPACE" is a mnemonic which can be used as a quick checklist when making policy, and stands for stands for "Messenger, Incentives, Norms, Defaults, Salience, Priming, Affect, Commitments, Ego". The aim of MINDSPACE is to help policy-makers come up with more effective measures, and in doing so get better outcomes for the public and society.

\section{Consumer Policy Toolkit - OECD, 2010}

This practical guide is designed to aid policymakers in using a systematic approach to identify and evaluate consumer problems and to develop, implement and review effective consumer policies so that consumer can play their role in ensuring a dynamic economy.

The report notes that work done in the field of behavioural economics has identified a number of important ways that consumer behaviour may deviate from the assumptions underlying the traditional market model and has enriched understanding of consumer behaviour in key areas (eg. making choices with uncertain outcomes, trade-offs between present decisions and long-term interests). In certain areas, such as designing information disclosures or evaluating situations involving default-setting, behavioural economics may provide important insights that could improve policy formulation. As behavioural economics continues to mature, the report underlines that there may be further implications for consumer policy. It is therefore an area that merits continued attention.

Test, Learn, Adapt: Developing Public Policy with Randomised Controlled Trials - UK Cabinet Office Behavioural Insights Team, 2012

Randomised controlled trials (RCTs) are the best way of determining whether a policy is working. The paper identifies 9 steps that are required to set up any RCT:

Test

1. Identify two or more policy interventions to compare (e.g. old vs new policy; different variations of a policy).

2. Determine the outcome that the policy is intended to influence and how it will be measured in the trial. 
3. Decide on the randomisation unit: whether to randomise to intervention and control groups at the level of individuals, institutions (e.g. schools), or geographical areas (e.g. local authorities).

4. Determine how many units (people, institutions, or areas) are required for robust results.

5. Assign each unit to one of the policy interventions, using a robust randomisation method.

6. Introduce the policy interventions to the assigned groups.

Learn

7. Measure the results and determine the impact of the policy interventions.

Adapt

8. Adapt your policy intervention to reflect your findings.

9. Return to Step 1 to continually improve your understanding of what works.

Assessing investors' risk tolerance through a questionnaire - Nadia Linciano, Paola Soccorso, Consob Italy Discussion paper 4, 2012

This paper reviews questionnaires used by investment firms to assess their potential clients' risk attitude before proposing an investment product. The objective was to identify major shortcomings, based in particular on behavioural insights, and suggest improvements. The study concludes that several limitations affect the content of the questionnaires used, in particular with regard to questions used to assess customers' investment knowledge and experience; the format used to elicit consumers' risk attitude which does not independently assess preferences on the time horizon and investment aims; the way questions on risk attitude are worded.

Applying behavioural economics at the Financial Conduct Authority - Kristine Erta, Stefan Hunt, Zanna Iscenko, Will Brambley, Financial Conduct Authority (FCA) Occasional Paper 1, 2013

People often make errors when choosing and using financial products, and can suffer considerable losses as a result. Using behavioural economics helps understand how these errors arise, why they persist, and what can be done to ameliorate them. Market forces left to themselves will often not work to reduce these mistakes, so regulation may be needed.

The paper summarises the main lessons from behavioural economics for retail financial markets: how consumers make predictable mistakes when choosing and using financial products, how firms respond to these mistakes; and how behavioural biases can lead firms to compete in ways that are not in the interests of consumers. It then describes how behavioural economics can, and should, be used in the regulation of financial conduct.

Encouraging consumers to claim redress: evidence from a field trial - Paul Adams, Stefan Hunt, FCA Occasional Paper 2, 2013

The report describes a research conducted to determine how to encourage consumers to claim redress following the mis-selling of financial products. Mis-sold customers needed to answer questions raised in the letter to get redress. The firm's original letter had a very low response rate. Different potential improvements to the firm's letter were tested using an RCT, with a view to increase the level of customers' response. The letter was modified with simple amendments, including reducing the amount of text, explaining to readers that the claims' process would only take five minutes, putting 
the main thrust of the message in bullets at the top of the letter, adding an "act quickly" label on the envelope and the FSA logo on the letter, replace the generic "Customer Team" signature by the CEO's. Reminders were also sent. Overall, the rate of responses jumped by over $10 \%$.

Applying Behavioural Sciences to EU Policy-making - René van Bavel, Benedikt Herrmann, Gabriele Esposito, Antonios Proestakis, European Commission, Joint Research Centre Scientific and Policy reports, 2013

This report is intended as a guide for EU policy-makers wishing to introduce a more refined understanding of human behaviour into the policy-making process. It covers specific issues that should be taken into account when incorporating behavioural insights into the design, implementation and monitoring of policies. This includes: identifying at what stage behavioural science should be applied to the policy-making process; defining the role of behaviour in a policy initiative; reviewing the available evidence; estimating the value added of a behavioural study; specifying the unit of analysis (usually individuals but firms in some cases, or SMEs; and considering time constraints. The paper also reviews the various types of behavioural studies that can be conducted to inform the envisaged EU policy: experimental study; randomised controlled trial (RCT); survey, or qualitative research.

Behavioural Economics and Competition Policy - The Netherlands Authority for Consumers and Markets (Autoriteit Consument \& Markt, ACM), 2013

The report explores what behavioural economics can mean for competition policy. It analyses the implications of the main behavioural economics findings for the effects of competition on consumer welfare and for the explanatory value of the theory underlying competition analysis. The report concludes that the findings of behavioural economics do not necessitate a re-evaluation of the fundamental basis and benefits of competition policy or the explanatory value of standard economic models. The report also discusses the issue of potential pockets of market power in which firms may exploit consumer biases. If dynamic learning effects are limited and exploitation of consumer biases appears persistent, regulators may decide to intervene. The ACM's view is that the enforcement of consumer protection laws, market scans and effective communication (to help 'de-bias' consumers) are the best instruments to deal with this issue.

Financial (Dis-)Information Evidence from an Audit Study in Mexico -Xavier Gine, Cristina Martinez Cuellar, Rafe Mazer, World Bank, 2014

In Mexico, the World Bank, CGAP and Condusef, the Mexican Consumer Protection Agency, trained lower-income consumers to pose as potential customers at financial institutions. Those "mystery shoppers" tested financial institutions in 4 towns and found significant gaps between what the law requires and what is actually happening on the ground. It showed for example that inexperienced consumers receive less product information during the sales process, as banks staff tend to treat customers differently based on their perceived financial knowledge. It also evidenced that sales staff incentives do not align with consumer needs and budgets: low-cost accounts, which are good for customers, are not generally profitable for banks and are not offered.

\section{Regulatory Policy and Behavioural Economics - Peter Lunne, OECD, 2014}

Over the last years, behavioural economics has been rapidly propelled from the margins of economic analysis towards the policy mainstream. In this context, this study offers an international review of the initial applications of behavioural economics to policy, with a particular focus on regulatory policy. It describes the extent to which behavioural findings have begun to influence public policy in a number of OECD countries, referring to a total of more than 60 instances, the majority of 
which concern regulatory policy. It then considers possible lessons for regulatory design and delivery, highlighting in particular that the introduction of a behavioural economics dimension in regulatory design will have implications for applied economic analysis and the skill-sets of those working in policy development and regulation with the conduct or commission of context-specific empirical studies that employ experiments, pilots and RCTs. It also underlines how much the environment in which decision makers operate matters. Regulations are just one possible way to alter that environment, but where they are effective it may often be less because they prohibit than because they assist; good regulations can improve the environment for decision makers.

Final report of the conference on Emerging challenges in retail finance and consumer policy European Commission, 2014

One of the conference's sessions focused on the ways to make a better use of the insights of behavioural economics in policymaking in the area of financial services. Recent EU legislative measures have attempted to integrate the psychological dimension of consumers' decision-making process (packaged-retail and insurance-based investments products - PRIIPs, Consumer and Mortgage Credit Directives), and the European Commission is interested in further learning and exploring how best to apply such insights in regulatory work. As part of the discussion, the European Consumer Organisation, BEUC, recognised the value of behavourial economics but underlined that more market failures which generate consumers' vulnerability have been so far insufficiently addressed by policymakers, for example: (artificial) complexity of financial products, tying of products or conflicts of interests arising from commissions and remuneration schemes. The Financial Conduct Authority highlighted that the UK has developed a model for regulatory analysis which looks at markets in the round by exploring the interaction of behavioural market failures, structural competition issues, information asymmetries, externalities and regulatory failures. Participants to the conference debated 4 preselected topics falling under the scope of behavioural economics: comparability of products, vulnerable consumers, providers' reputation and trustworthiness, and misalignment of incentives.

How does selling insurance as an add-on affect consumer decisions? A practical application of behavioural experiments in financial regulation - FCA Occasional Paper 3, 2014

This paper described the $1^{\text {st }}$ FCA behavioural experiment, which studies decision-making in a more stylised environment than a field trial, but still captures the main aspects of the decision that is being investigated. It formed part of the FCA market study on general insurance products commonly sold as add-ons, i.e. general insurance sold alongside other (primary) products either at the same time or subsequently, like travel insurance sold alongside a holiday. The study investigated whether there were common patterns across add-on markets that weakened competition and drove poor consumer outcomes. This involved considering various sales and price format: standalone insurance; add-on upfront alongside the primary product; add-on revealed only at point of sale for the primary product. This helped identify the effects on the extent and effectiveness of shopping around and on the add-on take up.

Behavioural Economics - Department of Public Expenditure and Reform's Central Expenditure Evaluation Unit, Irish Government Economic and Evaluation Service, 2014

This paper examines, in a preliminary way, the potential for the growing body of research and innovative ideas emerging in the area of behavioural economics to improve the effectiveness and efficiency of policies and of State services and service delivery to the citizen.

It explains the theoretical and research-based background to behavioural economics and discusses some practical applications in the area of public policy making and public service delivery. In doing 
so, it draws on examples of best international practices and makes some recommendations for applying these in Ireland. It also highlights existing good practices and initiatives underway in parts of the Irish public service. There is scope for behavioural economics across the wide spectrum of public policy and state services - health care, education, pensions, back-to-work initiatives, reducing reoffending rates, and the collection of taxes, fines and charges. This paper proposes that behavioural economics can improve new policy development, enhance the delivery of existing policy and interventions, help avoid unintended outcomes and improve productivity. At an operational level, behavioural economics has application across public services, including in the area of debt management and revenue collection, and at a policy level it can inform policy development in areas such as pensions and in health.

Applying behavioral insights in consumer protection policy - Rafe Mazer, Katharine McKee, Alexandra Fiorillo, CGAP, 2014

The increased use of behavioural research to develop consumer protection policies is especially important in emerging markets and developing economies (EMDEs) due to the nature of both their financial markets and many of their financial consumers. The paper explores how behavioural research can offer important tools for effective policy-making in four priority consumer protection topics that are relevant in virtually all settings, but have specific implications in base-of-the-pyramid settings: disclosure, transparency, and product choice; complaints handling and recourse; credit market regulation and debt stress; and fair treatment. Each of the four sections reviews emerging evidence and experience from behavioural research and offers specific advice for policy and regulation deriving from these behavioural insights. The paper closes with reflections on consumer protection-related priorities and challenges in EMDEs that would benefit from further applied behavioural research and field experimentation.

Investing in hybrid securities: explanations based on behavioural economics - Australian Securities and Investment Commission (ASIC), 2015

This report sets out the results of research into how behavioural biases may influence preferences towards hybrid securities over the less complex financial products of bonds and shares. It provides preliminary insight into the behavioural biases and risk attitudes that influence investment in hybrid securities. Findings show that they include the illusion of control that investors can exert over their environment; investors' overconfidence on their ability to withdraw from an investment early and consequently be protected from risk; a framing bias regarding the formulation of the choice in favour of hybrid securities; a preference of known risks over unknown risks; branding of (known) issuers of financial products; investors' risk perception and attitudes. The findings are based on a pilot study that was commissioned by ASIC due to its concern that some retail investors may struggle to understand the complexity of hybrid securities and the risks they pose.

Improving communication with directors of firms in liquidation - Australian Securities and Investment Commission (ASIC), 2015

Based on a behavioural economics approach, this report explores how to increase compliance of directors of companies in liquidation with their legal obligations to cooperate with a nominated liquidator. The research tests, through a laboratory experiment, potentially effective ways through changing the form of communication used when requesting company information from directors, and offering opportunities to receive legal or accounting assistance. Directors willing to comply but lacking business management skills appear to be more likely to react positively to "nudge-like" treatments. 
Stimulating interest: Reminding savers to act when rates decrease - FCA Occasional Paper 7, 2015

This paper analyses if holders of savings accounts with short-term high interest rates do not transfer their money when the rate falls because of behavioural biases, such as undervaluing long-term gains relative to short-term costs (present bias) or paying insufficient attention to their savings choices (limited attention). The FCA has carried out a trial involving savings account customers whose interest rate was about to decrease or had just decreased. All of these customers had already received a letter two to three months before the rate decrease informing them of this. This paper investigates the effects on switching behaviour of an additional letter, different messages in the reminder and the timing of the reminder.

Two plus two makes five? Survey evidence that investors overvalue structured deposits - FCA Occasional Paper 9, 2015

The survey investigated how well consumers understand and value structured deposits, a class of complex products. The FCA conducted a behavioural experiment involving retail investors who had previously bought or would consider buying structured deposits or other structured products. Investors significantly and systematically overestimated the return from structured deposits. This overestimation led them to prefer structured deposits over alternatives as cash savings. New targeted disclosure could improve how consumers make their comparisons and their investment decisions.

Financial Product Disclosure: Insights from Behavioural Economics - Kirsty Johnston, Christine Tether, Ashley Tomlinson, Ministry of Business, Innovation and Employment New Zealand, Occasional Paper 15/01, 2015

The paper reviews research on behavioural economics and identifies the main implications for the development of policy for financial product disclosure, with a focus on investment products. The conclusion is that disclosures are most effective at aiding investor decision making when they are short and simple; standardised; clear about risks and benefits; meaningful; well presented; and tested on investors. The reports also highlights that it is important that key behavioural insights are seen in the broader context of what a disclosure regime seeks to achieve (for example, a short and succinct document is not an end in itself if it fails to convey the necessary information), in order to effectively aid investors' understanding and decision making.

Message received? The impact of annual summaries, text alerts and mobile apps on consumer banking behaviour - FCA Occasional paper 10, 2015

In the context of a potential Competition and Markets Authority investigation into personal current accounts, the FCA wanted to understand the impact of previous initiatives that were intended to help consumers manage their current account. The experience showed that annual summaries have no effect on consumer behaviour in terms of incurring overdraft charges, altering balance levels or switching to other current account providers. In contrast, signing up to text alerts or mobile banking apps reduces the amount of unarranged overdraft charges incurred, and signing up to both services has an additional effect. The additional impact of the combination of both services shows the benefit of receiving information upon automatic triggers, without having to actively acquire it, as well as having the facility to act quickly upon receiving information. Text alerts and mobile banking apps also reduce current account balances, which is beneficial for consumers as they reduce the cost of holding funds in accounts with low credit interest rates. This research reinforces the importance of testing disclosures beforehand to help ensure that they effectively achieve their intended outcomes. The paper discusses 
wider implications for the role of regulation, how to design effective disclosure rules, and incentives for innovation.

\section{Newspaper articles and blog posts}

Economics Behaving Badly - George Loewenstein and Peter Ubel, New York Times, 14 July 2010

The article argues that behavioural economics is being asked to solve problems it was not meant to address and that in some cases, it is being used as a political expedient, allowing policymakers to avoid more effective solutions rooted in traditional economics. Behavioural economics should complement, not substitute for, more substantive economic interventions.

Pire que l'autre, la nouvelle science économique - Laura Raim, Le Monde Diplomatique, juillet 2013

Behavioural economics explores consumers' decision-making process in order to help them "follow the right path", through subtle incentives or nudges. But behavourial economics is also used by firms especially in the financial sector (eg. asset management funds), as a way to influence employees and clients' reactions to the firms' benefit. The article presents nudges as a midway solution between markets "laisser-faire" and public regulation. They would facilitate choices made in the general interest, without defining what this "general interest" is or should be. The article also points at the problematic connections between the economic and the political spheres. It expresses some doubts about the practical results of behavioural economics research and concludes that this approach fails to solve the market inefficiency problems. 


\section{WORKING PAPERS PUBLISHED TO DATE}

The full series is listed below in chronological order. Prior to March 2010, the series was named

OECD Working Papers on Insurance and Private Pensions. All working papers can be accessed online at: www.oecd.org/daf/fin/wp.

2016

WP.41 Unleashing the Export Potential of SMEs in Greece

WP.40 Financial Education Policies in Asia and the Pacific

2015

WP39: Financial Education for Long-term Savings and Investments: Review of Research and Literature

WP38: Financial Education for Migrants and their Families

2014

WP37: The Bitcoin Question: Currency versus Trust-less Transfer Technology

2013

WP36: Institutional Investors and Infrastructure Financing

WP35: Institutional Investors and Green Infrastructure Investments: Selected Case Studies

WP34: Promoting Financial Inclusion through Financial Education

WP33: Financial Education in Latin America and the Caribbean

WP32: Pension Fund Investment in Infrastructure: A Comparison between Australia and Canada

WP31: Policyholder Protection Schemes: Selected Considerations

WP30: The Effect of Solvency Regulations and Accounting Standards on Long-Term Investing

WP29: Trends in Large Pension Fund Investment in Infrastructure

WP28: Communicating Pension Risk to DC Plan Members: The Chilean Case of a Pension Risk Simulator

WP27: The Role of Funded Pensions in Retirement Income Systems: Issues for the Russian Federation

WP26: Infrastructure Investment in New Markets: Challenges and Opportunities for Pension Funds

WP25: The Status of Financial Education in Africa 
WP24: Defining and Measuring Green Investments: Implications for Institutional Investors' Asset Allocations

WP23: The Role of Institutional Investors in Financing Clean Energy

WP22: Defining and Measuring Green Investments: Implications for Institutional Investors' Asset Allocations

WP21: Identification and Assessment of Publicly Available Data Sources to Calculate Indicators of Private Pensions

WP20: Coverage of Private Pensions Systems: Evidence and Policy Options

WP19: Annual DC Pension Statements and the Communications Challenge

WP18: Lessons from National Pensions Communication Campaigns

WP17: Review of the Swedish National Pension Funds

WP16: Current Status of National Strategies for Financial Education

WP15: Measuring Financial Literacy: Results of the OECD International Network on Financial Education (INFE) Pilot Study

WP14: Empowering Women through Financial Awareness and Education

WP13: Pension Fund Investment in Infrastructure: Policy Actions

WP12: Designing Optimal Risk Mitigation and Risk Transfer Mechanisms to Improve the Management of Earthquake Risk in Chile

2011

WP11: The Role of Guarantees in Defined Contribution Pensions

WP10: The Role of Pension Funds in Financing Green Growth Initiatives

WP9: Catastrophe Financing for Governments

WP8: Funding in Public Sector Pension Plans - International Evidence

WP7: Reform on Pension Fund Governance and Management: The 1998 Reform of Korea National Pension Fund

WP6: Options to Improve the Governance and Investment of Japan's Government Pension Investment Fund

WP5: The New IAS 19 Exposure Draft

WP4: The EU Stress Test and Sovereign Debt Exposures

WP3: The Impact of the Financial Crisis on Defined Benefit Plans and the Need for CounterCyclical Funding Regulations

WP2: Assessing Default Investment Strategies in Defined Contribution Pension Plans

WP1: Framework for the Development of Financial Literacy Baseline Surveys: A First International Comparative Analysis 


\section{OECD Working Papers on Insurance and Private Pensions}

WP41: Policy Action in Private Occupational Pensions in Japan since the Economic Crisis of the 1990 s

WP40: Pension Funds' Risk-management Framework: Regulation and Supervisory Oversight

WP38: Managing Investment Risk in Defined Benefit Pension Funds

WP37: Investment Regulations and Defined Contribution Pensions

WP36: Private Pensions and Policy Responses to the Financial and Economic Crisis

WP35: Defined-contribution (DC) arrangements in Anglo-Saxon Countries

WP34: Evaluating the Design of Private Pension Plans

WP33: Licensing Regulation and the Supervisory Structure of Private Pensions

WP32: Pension Fund Investment in Infrastructure

WP31: Pension Coverage and Informal Sector Workers

WP30: Pensions in Africa

WP29: Ageing and the Payout Phase of Pensions, Annuities and Financial Markets

WP27: Fees in Individual Account Pension Systems

WP26: Forms of Benefit Payment at Retirement

WP25: Policy Options for the Payout Phase

WP24: National Annuity Markets

WP23: Accounting for Defined Benefit Plans

WP22: Description of Private Pension Systems

WP21: Comparing Aggregate Investment Returns in Privately Managed Pension Funds

WP20: Pension Fund Performance

WP19: Coverage of Funded Pension Plans

WP18: Pension Fund Governance

WP17: Funding Regulations and Risk Sharing

WP16: Evaluating the Impact of Risk Based Funding Requirements on Pension Funds

WP15: Governance and Investment of Public Pension Reserve Funds in Selected OECD Countries

WP14: Sovereign Wealth and Pension Fund Issues 
WP13: Reforming the Valuation and Funding of Pension Promises

WP12: Pension Fund Investment in Hedge Funds

WP11: Implications of Behavioural Economics for Mandatory Individual Account Pension Systems

WP10: Portfolio Investment in an Intertemporal Setting

WP9: Collective Pension Funds

WP8: Pension Fund Regulation and Risk Management

WP7: Survey of Investment Choice by Pension Fund Members

WP6: Benefit Protection

WP5: Benefit Security Pension Fund Guarantee Schemes

WP4: Governments and the Market for Longevity-Indexed Bonds

WP3: Longevity Risk and Private Pensions

WP2: Policy Issues for Developing Annuities Markets

WP1: Funding Rules and Actuarial Methods 